\title{
Diversity and Versatility in Small RNA-Mediated Regulation in Bacterial Pathogens
}

\author{
Brice Felden ${ }^{\dagger}$ and Yoann Augagneur* \\ Inserm, Bacterial Regulatory RNAs and Medicine (BRM) - UMR_S 1230, Rennes, France
}

Bacterial gene expression is under the control of a large set of molecules acting at multiple levels. In addition to the transcription factors (TFs) already known to be involved in global regulation of gene expression, small regulatory RNAs (sRNAs) are emerging as major players in gene regulatory networks, where they allow environmental adaptation and fitness. Developments in high-throughput screening have enabled their detection in the entire bacterial kingdom. These sRNAs influence a plethora of biological processes,

OPEN ACCESS

Edited by:

Olga Soutourina, UMR9198 Institut de Biologie Intégrative de la Cellule (I2BC),

France

Reviewed by:

Teppei Morita,

Keio University, Japan

Young Min Kwon,

University of Arkansas, United States

*Correspondence:

Yoann Augagneur

yoann.augagneur@univ-rennes1.fr

${ }^{\dagger}$ Deceased

Specialty section:

This article was submitted to Microbial Physiology and Metabolism,

a section of the journal

Frontiers in Microbiology

Received: 03 June 2021

Accepted: 20 July 2021

Published: 10 August 2021

Citation:

Felden B and Augagneur Y (2021)

Diversity and Versatility in Small

RNA-Mediated Regulation in

Bacterial Pathogens.

Front. Microbiol. 12:719977.

doi: 10.3389/fmicb.2021.719977 including but not limited to outer membrane synthesis, metabolism, TF regulation, transcription termination, virulence, and antibiotic resistance and persistence. Almost always noncoding, they regulate target genes at the post-transcriptional level, usually through base-pair interactions with mRNAs, alone or with the help of dedicated chaperones. There is growing evidence that sRNA-mediated mechanisms of actions are far more diverse than initially thought, and that they go beyond the so-called cis- and trans-encoded classifications. These molecules can be derived and processed from 5' untranslated regions (UTRs), coding or non-coding sequences, and even from 3' UTRs. They usually act within the bacterial cytoplasm, but recent studies showed sRNAs in extracellular vesicles, where they influence host cell interactions. In this review, we highlight the various functions of sRNAs in bacterial pathogens, and focus on the increasing examples of widely diverse regulatory mechanisms that might compel us to reconsider what constitute the sRNA.

Keywords: bacterial regulatory RNAs, noncoding RNAs, pathogens, small regulatory RNAs, small RNAs, sRNAs

\section{INTRODUCTION: A HISTORICAL OVERVIEW OF REGULATORY RNA DISCOVERIES}

The central dogma of molecular biology states that DNA is replicated or transcribed into RNA, and that RNA is translated into proteins (Crick, 1958, 1970). This has contributed to the understanding (or perhaps widespread belief) that RNAs are just unstable intermediates (Pennisi, 2010). However, extensive research into these molecules has revealed that their purpose is not always to be translated. This has resulted in the identification of a new class called noncoding RNAs, which have gradually been shown to have a seemingly infinite range of biological functions and mechanisms of action (Cech and Steitz, 2014). 
The first discoveries and characterizations of noncoding RNAs appeared in the late 1950s with the publication of studies on tRNA (Hoagland et al., 1958) and then rRNA (Cotter et al., 1967), both involved in protein translation. Various small noncoding RNAs (sRNAs) were subsequently identified in prokaryotes, with some being defined as regulatory RNAs due to their involvement in modulating bacterial metabolism (Wassarman et al., 1999). This was the case for 4.5S, transfermessenger RNA (tmRNA), ribonuclease P (RNaseP) RNA, and $6 \mathrm{~S}$, all initially identified by fractionation in the late 1960s (Hindley, 1967). 4.5S is a 114-nucleotide (nt) component of the signal recognition particle (SRP) involved in protein secretion (Luirink and Dobberstein, 1994). It is essential, normally associates with ribosomes, and processed to be functional. tmRNA is a highly stable RNA that requires processing at the 5 ' and 3' ends by RNaseP and RNaseIII, respectively (Wassarman et al., 1999). It has sequential tRNA- and mRNA-like properties, and is involved in trans-translation for rescue of stalled ribosomes and protein degradation promotion (Janssen and Hayes, 2012). Initially identified as "10Sb" (Hindley, 1967), RNaseP is an essential RNA processed at the 3' end by RNaseE, and it forms a ribonucleoprotein complex with the RNaseP protein (Altman et al., 1989). RNaseP is responsible for the maturation of tRNA 5 ' termini, an essential step preceding the aminoacylation of mature tRNAs. In vitro studies on RNaseP revealed that the RNA moiety is the catalytic subunit (Guerrier-Takada et al., 1983), paving the way for the concept of ribozyme and later to that of the RNA world (Gilbert, 1986). One distinctive feature of RNaseP is that the RNA moiety recognizes a tRNAlike structure rather than Watson-Crick complexes, thus permitting the cleavage and maturation of 4.5S RNA or tmRNA or else the development of RNaseP-mediated RNA therapeutics through gene-selective mRNA cleavage (Augagneur et al., 2012; Kole et al., 2012; Derksen et al., 2015). The first non-rRNA, non-tRNA to be sequenced was 6S RNA from Escherichia coli (Brownlee, 1971), although it took almost 30 years for its role in sequestering the $\sigma 70$ subunit of RNA polymerase to be demonstrated (Wassarman et al., 1999).

Meanwhile, other sRNAs including Spot42 and MicF were being discovered in E. coli (Ikemura and Dahlberg, 1973; Mizuno et al., 1984), and RNAI and RNAIII were soon thereafter discovered in the pathogen Staphylococcus aureus (Novick et al., 1989, 1993). As sRNAs were being discovered in virtually all bacteria, their regulatory mechanisms and biological functions began to be elucidated, bringing this class into the spotlight. Typically, sRNAs bind their target(s) (most often other RNAs by base-pairing and in a limited number of cases proteins) to modulate their expression at post-transcriptional level by influencing their stability and/or translation. However, it turns out that as a great variety of mechanisms was unraveled, a profusion of sRNA sub-categories emerged, and these regulatory RNAs began to be characterized as cis-encoded, trans-encoded, cis-acting, trans-acting, or even as sRNA-binding proteins. In eukaryotes, a similar abundance of non-mRNAs have been described. These include microRNAs, small interfering RNAs, Piwi-interacting RNAs, small noncoding RNAs, long noncoding RNAs, and circular RNAs, with these last ones acting as
microRNA sponges in the cytoplasm (Chen et al., 2015; Burenina et al., 2017). It is therefore clear that the term "RNA" encompasses molecules that have a plethora of biological traits and mechanisms in both prokaryotes and eukaryotes (Cech and Steitz, 2014). In this review, we summarize, in a non-exhaustive manner, the current knowledge on sRNAs in bacterial pathogens, with a particular focus on S. aureus, Listeria monocytogenes, and Salmonella. We use specific examples to describe some usual and unusual features of this heterogenous group of transcripts whose precise categorization appears to be much more complicated than initially expected.

\section{SRNA REGULATION IS REQUIRED FOR A VARIETY OF BIOLOGICAL FUNCTIONS}

Small regulatory RNAs are often described according to categories based on genome localization and their featured regulatory mechanisms. In this review, we take an opposite view, and start by discussing the diversity of biological functions in which sRNAs play a role. They are not constitutively expressed, but instead respond to environmental variations to modulate the gene expression of numerous targets (Wagner and Romby, 2015). These specific conditions include transition to the stationary phase, thermal shock, oxidative stress, and many other environmental challenges. Although, there are few sRNAs conserved over the bacterial kingdom (structural "housekeeping" sRNAs such as 6S, tmRNA, and RNaseP), they are often species- or order-specific. They have substantial advantages over transcription factors (TFs); they require less energy for production since translation initiation is unnecessary; they can act faster and reversibly; and they can still bind to multiple targets, which allow them to regulate a wide range of biological functions.

\section{sRNAs and Their Involvement in Virulence}

In bacterial pathogens, it was an open question whether sRNAs were required for regulating virulence, either as activators or repressors. As sRNA molecular targets were being identified and regulatory functions in multiple pathways revealed, evidence has progressively emerged regarding their role in the direct or indirect control of virulence factors or the TFs that regulate virulence.

In $S$. aureus, the main sRNA involved in the commitment to virulence and quorum-sensing (QS) is RNAIII, an unusual 514-nt RNA that has an internal sequence coding for $\delta$-hemolysin (Novick et al., 1993). RNAIII responds to cell density through the agr QS system and its TF, AgrA. The sRNA accumulates during bacterial growth, reaching a maximal concentration during the post-exponential phase (Singh and Ray, 2014). In doing this, it coordinates the transition from colonization to infection by directly or indirectly reprogramming the expression of a large set of genes (Bronesky et al., 2016; Table 1). Among the various virulence factors, RNAIII represses the expression of the TF Rot (Geisinger et al., 2006; Boisset et al., 2007), 
TABLE 1 | Targets regulated by RNAlll.

\begin{tabular}{|c|c|c|c|}
\hline Target & RNAIII effect & $\begin{array}{l}\text { Encoded target } \\
\text { function }\end{array}$ & $\begin{array}{l}\text { Mechanism of } \\
\text { action }\end{array}$ \\
\hline spa & Repression & $\begin{array}{l}\text { Adhesion and } \\
\text { immune evasion }\end{array}$ & $\begin{array}{l}\text { Translation } \\
\text { inhibition and }\end{array}$ \\
\hline coa & & Adhesion & degradation by \\
\hline sa1000 & & Adhesion & RNaselll \\
\hline rot & & $\begin{array}{l}\text { Transcription } \\
\text { factor and toxin } \\
\text { repressor }\end{array}$ & \\
\hline$s b i$ & & $\begin{array}{l}\text { Adhesion and } \\
\text { immune evasion }\end{array}$ & $\begin{array}{l}\text { Translation } \\
\text { inhibition }\end{array}$ \\
\hline lytM & & $\begin{array}{l}\text { Cell-wall } \\
\text { metabolism and } \\
\text { release of Spa }\end{array}$ & $\begin{array}{l}\text { Translation } \\
\text { inhibition }\end{array}$ \\
\hline hla & Activation & Alpha toxin & $\begin{array}{l}\text { Translation } \\
\text { activator }\end{array}$ \\
\hline$m g r A$ & & $\begin{array}{l}\text { Transcription } \\
\text { factor, inhibitor of } \\
\text { surface proteins } \\
\text { and autolysis, and } \\
\text { activator of } \\
\text { capsule synthesis }\end{array}$ & $\begin{array}{l}\text { Stabilization of } \\
\text { mRNA }\end{array}$ \\
\hline
\end{tabular}

a repressor of numerous exotoxins that positively controls surface proteins such as Spa (Saïd-Salim et al., 2003; Oscarsson et al., 2006). By inhibiting this TF, RNAIII indirectly activates exotoxin production and inhibits surface protein expression. RNAIII and Rot inverted effects allow an effective switch between defense and offensive mode called Double Selector Switch (DSS; Nitzan et al., 2015). RNAIII also represses the expression of Spa, Coa, LytM, and Sbi by inhibiting ribosome binding or sometimes by promoting mRNA degradation (Table 1). Conversely, it upregulates the expression of $\alpha$-hemolysin (Hla; $\alpha$-toxin; Morfeldt et al., 1995) and MgrA TF, which inhibits surface protein expression (Luong et al., 2006; Gupta et al., 2015). We describe the actual mechanisms of actions against these targets later on in this review.

Other S. aureus, sRNAs participate in virulence gene regulation, including SprD, the sRNA expressed from a pathogenicity island (Pichon and Felden, 2005). SprD downregulates the expression of Sbi, an immune evasion factor, at translational level (Chabelskaya et al., 2010). In the same study, the authors showed that the deletion of SprD resulted in the generation of a lessvirulent strain in the mouse model of infection. This suggests that SprD controls the expression of other factors through yet-unknown mechanisms. Interestingly, Sbi is tightly controlled by both SprD and RNAIII, which are not expressed in S. aureus under the same conditions, and this suggests complementary roles for these two sRNAs in Sbi expression (Chabelskaya et al., 2014). Several other examples of sRNAs that positively or negatively control virulence exist in this bacterium, including SSR42, SprC, and RsaA (Morrison et al., 2012; Romilly et al., 2014; Le Pabic et al., 2015; Das et al., 2016).

In another low GC-content human pathogen L. monocytogenes, several sRNAs contribute to virulence (Toledo-Arana et al., 2007, 2009; Gripenland et al., 2010; Mellin and Cossart, 2012; Quereda and Cossart, 2017). First line of evidences came out with the deletions of blood-induced rli38 and rliB, which resulting in attenuated or increased tissue colonization in a mouse model of infection, respectively. A study of Listeria's intracellular transcriptome during growth in macrophages identified a large set of sRNAs, three of which (Rli31, Rli33-1, and Rli50) are directly associated with virulence (Mraheil et al., 2011). In addition, during intracellular growth, the bloodinduced sRNA Rli27 upregulates the expression of Lmo0514, a cell-wall protein that has a pivotal role in virulence, as it is required for survival in plasma and for virulence in mice (Quereda et al., 2014, 2016).

In Gram-negative pathogens, most studies have focused on Salmonella Typhimurium and enterohemorrhagic E. coli (EHEC). In Salmonella, IsrM is a pathogenicity island-encoded sRNA with interesting features (Gong et al., 2011). Although, non-essential during growth in vitro, it is upregulated during infection, with high levels in the ileum. IsrM targets the SpoA and HilE mRNAs, which control the expression of Salmonella pathogenicity island 1 (SPI-1) genes. Deletion of isrM affects the bacterial invasion of epithelial cells, intracellular replication/ survival in macrophages, and virulence in mice. In E. coli O157:H7 strain, several sRNAs are involved in virulence (Sauder and Kendall, 2018). Interestingly, the functions regulated by sRNAs differ in nonpathogenic E. coli and in EHEC, where core genome-encoded sRNAs can regulate virulence factors carried in pathogenicity islands. These include GlmY and GlmZ, sRNAs which control amino-sugar metabolism in nonpathogenic E. coli (Gruber and Sperandio, 2015) as well as being involved in type III secretion machinery in EHEC (Gruber and Sperandio, 2014). Similar to $S$. aureus, EHEC contains pathogenicity islandencoded sRNAs such as the antisense sRNAs Arl and sRNA350, both of which regulate bacterial virulence (Tobe et al., 2014; Bhatt et al., 2016). Additionally, some sRNAs such as DicF have both core genome-encoded and pathogenicity islandencoded copies (Melson and Kendall, 2019). When oxygen is limited, DicF binds $p c h A$ mRNAs, which encode a transcriptional activator of the type III secretion system. This allows access to the $p c h A$ ribosome binding site (RBS), promoting the expression of the activator and thereby increasing virulence (Melson and Kendall, 2019). Recent work on the sRNA, RyfA revealed its roles in virulence (mouse model) and survival (in human primary macrophages), both carried out by regulating genes coding for cell surface proteins and biofilm formation (Bessaiah et al., 2021). Other examples of sRNAs involved in virulence were reported in Pseudomonas aeruginosa, Vibrio cholerae, and Helicobacter pylori, and these have been thoroughly discussed in several articles and reviews (Pitman and Cho, 2015; Svensson and Sharma, 2016; Vannini et al., 2016; Ferrara et al., 2017; Quereda and Cossart, 2017; Zhao et al., 2018; Kinoshita-Daitoku et al., 2021).

\section{The Role of sRNAs in Host-Pathogen Interactions}

In most of the examples discussed above, researchers began by identifying sRNAs and their targets in laboratory conditions or using in silico strategies before moving on to testing sRNAdeleted strains in animal models. These laboratory conditions 
only partially reproduce environmental cues, so some sRNA functions may be underestimated. Recently, the advent of deepsequencing technologies filled in many blanks, enabling the study of sRNA expression and functions directly during hostpathogen interactions. Originally, the sRNA EsrF was predicted from transcriptomic data generated during EHEC infection of HeLa cells (Yang et al., 2015). EsrF senses high ammonium concentrations in the colon and promotes bacterial motility, host cell adhesion, and virulence in the colon (Jia et al., 2021). In Salmonella, dual RNA sequencing (RNA-seq) analysis revealed an activation of PinT during infection (Westermann et al., 2016). Similar to RNAIII, this sRNA plays an important role in chronological control of virulence factor expression in order to push the bacteria from the invasive to the virulent mode. PinT controls the SPI-1 and SPI-2 effectors required for intracellular survival, and causes pervasive changes in $\sim 10 \%$ of the host's coding and noncoding transcripts. A recent study using a novel MS2 affinity purification coupled with RNA sequencing (MAPS) technique (Lalaouna et al., 2017) in macrophages elegantly identified SteC, a novel PinT ligand that affects host actin rearrangement during infection (Correia Santos et al., 2021). The use of such new techniques should be extended to other pathogens, paving the way for the discovery of more sRNAs and new and better knowledge about their biological functions.

Another interesting thing about sRNAs is that their delivery into host cells from outer membrane vesicles allows them to modulate host-pathogen communications. While the characterization of sRNA content in extracellular vesicles is quite recent, links between sRNAs and host immune response were reported in P. aeruginosa, $H$. pylori, and Vibrio fischeri (Koeppen et al., 2016; Moriano-Gutierrez et al., 2020; Zhang et al., 2020). The RNA cargo of S. aureus was also recently characterized, revealing that the sRNAs RNAIII, RsaC, and SsrA (tmRNA) predominate. This suggests additional functions for these sRNAs in the control of immune host response (Joshi et al., 2020; Luz et al., 2021), as suggested in earlier reviews (Ellis and Kuehn, 2010; Avila-Calderón et al., 2015).

\section{sRNA-Mediated Antimicrobial Responses and Resistance}

Although, the study of sRNAs and their roles in pathogenicity has inspired growing interest and uncovered new features, the biological functions of sRNAs go far beyond virulence. Besides being pathogenic, the emergence of bacterial strains resistant to antibiotic treatments is a serious public health issue, and several studies have therefore looked for correlations between sRNA expression and antibiotic challenges. These contributions to a better understanding of bacterial resistance and the role of sRNAs in these networks were recently reviewed (Felden and Cattoir, 2018).

In Salmonella, four sRNAs (sYJ5, SroA, sYJ75, and sYJ118) are upregulated when subjected to half the MIC of tigecycline (Yu and Schneiders, 2012), and the genetic deletion of sroA leads to reduced viability in the presence of that antibiotic. SroA exhibits the structural characteristics of a riboswitch, although its mechanism of action has not yet been characterized.
In E. coli, RyhB is induced upon iron starvation, and it represses the expression of a large set of genes as well as participating in iron homeostasis (Massé and Gottesman, 2002; Chareyre and Mandin, 2018). During iron starvation, it is also involved in sensitivity to colicin Ia, an E. coli-specific bacteriocin produced to kill other E. coli strains (Salvail et al., 2013). To do this, RyhB binds cirA mRNAs, thereby activating its translation. CirA is a colicin Ia receptor and allows its translocation into the cell. Another study reported on the role of RyhB in antibiotic resistance after testing four classes of antibiotics (aminoglycosides, $\beta$-lactams, fluoroquinolones, and tetracycline; Chareyre et al., 2019). The authors showed that during iron starvation $r y h B$ mutants were more susceptible to the aminoglycoside gentamicin as a result of the derepression of respiratory complexes Nuo and Sdh.

In $P$. aeruginosa, at least three sRNAs are known to be required for carbapenem resistance (Zhang et al., 2017; Sonnleitner et al., 2020). In the first study, Hi-GRIL-seq identified Sr0161 and ErsA as sRNA repressors of OprD, a porin involved in carbapenem antibiotic uptake. Their roles were functionally demonstrated in their respective deleted strains, in which meropenem susceptibility was significantly increased (Zhang et al., 2017). In the same article, Sr006 was shown to be involved in resistance to polymyxin $\mathrm{B}$ through the translation activation of PagL, an enzyme involved in lipopolysaccharide synthesis. In the second study, the sRNA CrcZ was shown to regulate carbapenem susceptibility through an indirect mechanism (Sonnleitner et al., 2020). By sequestering the Hfq protein when the preferred carbon source is exhausted, CrcZ prevents Hfq-mediated translational repression of OprP, another porin involved in carbapenem entry. Other studies have emphasized the role of sRNAs in $P$. aeruginosa and other Enterobacteriaceae, and are summarized in a recent review (Mediati et al., 2021).

In S. aureus, antibiotic exposure causes the specific expression of several sRNAs in the multidrug-resistant strain JKD6008 (Howden et al., 2013). Recently, the same authors identified a set of 18 sRNAs whose expressions vary under linezolid treatment (Gao et al., 2020). Although, no phenotypic variations were observed after genetic deletions of these sRNAs, which questions their actual roles in antibiotic resistance/adaptation, other studies have given direct evidence of direct sRNA involvement in antibiotic resistance. Depending on the strain, the sRNA SprX is encoded in one or more copies, and it inhibits translation of the SpoVG TF involved in glycopeptide and oxacillin resistance (Eyraud et al., 2014). The direct role of this sRNA was confirmed, as its deletion leads to moderately increased resistance, while its overexpression results in glycopeptide susceptibility. Antibiotic treatment failure is also largely attributed to the formation of persister cells, a subpopulation which is transiently tolerant of various antibiotic classes following entry into dormancy. A recent work identified the RNA antitoxin SprF1 in S. aureus as an RNA factor promoting persistence when challenged by ciprofloxacin and vancomycin at high doses (20x and $80 \mathrm{x}$ the MIC, respectively; Pinel-Marie et al., 2021). The authors demonstrated that this sRNA binds 70S ribosomes to slow translation and favor the 
entry into persistence, allowing survival until the antibiotic treatment is discontinued.

\section{sRNAs Span Many Other Functions}

Studies of sRNAs in bacterial pathogens spotlight those involved in virulence or antibiotic resistance. However, many are involved in the regulation of other biological functions, especially fitness and adaptation. This is the case for instance for RsaE, RsaI, and $\mathrm{RsaD}$ in $S$. aureus. RsaE is the sRNA of about $100 \mathrm{nt}$ which was identified by bioinformatics in intergenic regions (Geissmann et al., 2009), and which is conserved in Bacillales (Bohn et al., 2010). Transcriptomic and 2D-DIGE analysis of an $r s a E$ mutant showed that this sRNA is involved in the regulation of several pathways connected to central metabolism, including the TCA cycle and metabolism of folate and malate. The first two targets to be characterized were the operonencoded mRNAs oppA and oppB (Geissmann et al., 2009; Bohn et al., 2010). A subsequent search for molecular targets uncovered its role in arginine catabolism, with the arginase RocF downregulated when RsaE binds the mRNA (Rochat et al., 2018). In Staphylococcus epidermidis, a species which could become a threat due to spreading multidrug-resistant strains (Lee et al., 2018), RsaE participates in the regulation of the composition of the extracellular matrix (Schoenfelder et al., 2019). To do so, the sRNA undergoes processing which results in two forms regulating different targets (Lee et al., 2018). While the longer transcript interacts with $\operatorname{lrg} A$ mRNA (Rice et al., 2005) to cause both RNA decay and translational attenuation, the shorter species binds icaR mRNA (Cue et al., 2012) to inhibit translation. Staphylococcus aureus RsaI is the sRNA whose expression is tightly controlled by CcpA, a global regulator of carbon catabolite repression (Seidl et al., 2009; Bronesky et al., 2019). It is inhibited under high concentrations of glucose, and this is alleviated during the growth stationary phase (Geissmann et al., 2009). An in-depth characterization of the targetome using MAPS uncovered mRNA targets involved in sugar metabolism, glucose uptake, and biofilm formation, including mRNA transcription factors and remarkably, other sRNAs such as RsaE, RsaD, and RsaG (Bronesky et al., 2019). Among the target characterized, RsaI primirally acts as a posttranscriptional repressor. RsaD was discovered at the same time with other Rsa sRNAs (Geissmann et al., 2009). It might be part of the RsaI regulon, and is induced upon nitric oxide challenge (Bronesky et al., 2019). A study of the CodY regulon identified RsaD as a direct molecular target, and computational tools enabled the authors to find various RsaD mRNA targets including alsS, which encodes $\alpha$-acetolactate synthase (Augagneur et al., 2020). Through post-transcriptional repression of alsS, $\mathrm{RsaD}$ redirects carbon overflow metabolism and regulates cell death during exposure to a weak acid stress.

In Salmonella Typhimurium, RydC was the first sRNA characterized as a regulator of membrane stability, binding $c f a$ mRNAs and encoding cyclopropane fatty-acid (CFA) synthase (Fröhlich et al., 2013). Unlike most of the sRNAs discussed above, RydC upregulates CFA synthase by stabilization its mRNA. Other sRNAs such as RybB and MicA maintain envelope homeostasis (Papenfort et al., 2006), with RybB spurring the degradation of omp mRNAs upon activation of the envelope stress response, while MicA controls their decay.

SgrS is another sRNA that promotes the expression of some of its targets (Papenfort et al., 2013). This sRNA is involved in glucose homeostasis through the activation and repression of several targets (Vanderpool and Gottesman, 2004). SgrS was first identified as a repressor of the phosphotransferase system (PTS), preventing the translocation of sugars into cells when the intracellular concentration of phosphorylated sugars is too high (Vanderpool and Gottesman, 2004). The sRNA also activates the translation of YigL, a phosphatase involved in detoxification of phosphosugars, thereby allowing diffusion of dephosphorylated sugars outside the cell membrane (Papenfort et al., 2013). While GlmY and GlmZ are both involved in virulence in EHEC (see section above on sRNAs and Their Involvement in Virulence), they also have other conserved regulatory activities in nonpathogenic $E$. coli, including amino sugar metabolism and cell envelope synthesis (Urban and Vogel, 2008; Göpel et al., 2014; Sauder and Kendall, 2018).

Initially identified in nonpathogenic E. coli, RyhB is involved in iron homeostasis, a critical factor in cellular processes (Massé and Gottesman, 2002). It is under the control of Fur, the TF that represses iron acquisition genes and RyhB when iron is abundant. RyhB downregulates iron-storing and iron-using proteins and these are therefore indirectly activated when Fur represses RyhB. In Salmonella, two paralogs have been identified: RyhB-1 and RyhB-2 (Kim, 2016). These share a 33-bp sequence with perfect identity, and can thus regulate the same targets (Kim and Kwon, 2013). Although their promoters are recognized by Fur, their expression profiles vary (Padalon-Brauch et al., 2008): $r y h B-1$ is induced under iron-depleted conditions or oxidative stress, while maximal ryhB-2 expression is seen during the stationary phase. Additional roles for RyhB paralogs were reported in Salmonella (Kim, 2016). These include involvement in nitrate homeostasis (Teixidó et al., 2010), oxidative stress, intracellular survival in macrophages, and control of SPI-1 and Type III secretion system gene expression (Leclerc et al., 2013; Calderón et al., 2014; Peñaloza et al., 2021).

DapZ is an 80-nt sRNA identified in Salmonella and transcribed from the 3 ' region of $d a p B$ (Chao et al., 2012). It is involved in the uptake of nutrient and signaling molecules. Via base-pairing, DapZ modulates the synthesis of $\mathrm{ABC}$ transporters Opp and Dpp, which encode oligopeptide and dipeptide permeases, respectively.

The ensemble of sRNA studies highlights their roles in many biological functions ranging from virulence to antibiotic resistance, and even including the regulation of TF expression and transcription termination. While sRNA research involving bacterial pathogens has often concentrated on virulence or antibiotic resistance because of public health issues, they are actually involved in all aspects of bacterial biology. There are about as many sRNAs discovered as TFs factors inventoried, which indicates that sRNAs are among the key players in transcriptional and post-transcriptional regulation of gene expression.

Just as there has been a large number of biological functions identified, the functional categorization of their mechanisms 
of production or regulation is broad and diverse, with new features constantly unraveled. sRNAs are a heterogeneous group of transcripts with lengths usually ranging from 50 to 500 nucleotides. They are usually highly structured, have greater stability than mRNAs, and use their base-pairing abilities to interact with and regulate their targets. To promote interaction with a target, a chaperone is sometimes necessary (Kavita et al., 2018). Based on their features, they can be categorized in multiple manners. In the following sections, we will first present the canonical features and mechanisms of action, then use selected examples to illustrate original features to showcase the diversity and versatility uncovered at the same time as the discovery of sRNAs exploded, suggesting that more surprises are in store.

\section{SRNAs THAT INTERACT WITH PROTEINS}

While most sRNAs use base-pairing to activate or repress the expression of their targets, some bind proteins to form ribonucleoprotein complexes (Pichon and Felden, 2007). These complexes are involved in the metabolism of DNA (regulation of plasmids and DNA transfers), RNAs, and proteins. When it comes to RNA metabolism, sRNAs can be involved in transcription through 6S sRNAs, in RNA maturation via RNAseP, or subject to decay when recognized by endo- or exo-ribonucleases (Wassarman et al., 1999; Hausmann et al., 2017; Redder, 2018; Le Scornet and Redder, 2019). In addition, some are assisted by trans-acting chaperones to facilitate recognition of "bait" and "prey" (Pichon and Felden, 2007). At protein level, they are important for global translation machinery and quality control (including tmRNAs involved in ribosome rescue), for protein trafficking with SRP and 4.5S RNA, and for sequestration of global regulators. Most of these characteristics are beyond the scope of this review, and we will just discuss the need for protein chaperones to stabilize interactions as well as the role of sRNAs in protein sequestration, both usually found in Gramnegative bacteria.

\section{The Role of Protein Chaperones in Stabilizing RNA-RNA Interactions}

In Gram-negative bacteria, the activity of numerous sRNAs relies on them acting in concert with a RNA chaperone protein. The most prevalent of these is Hfq, often referred to as the "RNA matchmaker" (Updegrove et al., 2016). Hfq is a homohexameric ring-shaped protein with at least three different RNA-binding domains shared between the rim and the proximal and distal faces of the hexamer (Gorski et al., 2017; Carrier et al., 2018). The proximal face specifically recognizes U-rich tracts, often associated with rho-independent transcription terminators, whereas the distal face anneals sRNAs through A-rich regions. Similar to the proximal face, the rim of the hexamer also binds U-rich regions. Not only does the binding with Hfq stabilize the sRNA and protect it from RNases, but also its ability to bind simultaneously with mRNAs and favors the formation of mRNA-sRNA duplexes. Indeed, this feature allows for the appropriate presentation of the sRNA seed region to an mRNA target, which in turn affects mRNA stability or translation (Figure 1). With the help of Hfa, only a short and conserved sRNA seed sequence is necessary for annealing with the target and promotion of regulatory activity. For instance, just seven nucleotides are responsible for the degradation of omp mRNAs by RybB (Balbontín et al., 2010; Papenfort et al., 2010). In addition to its RNA chaperone activity, Hfq can also directly influence translation by binding the $5^{\prime}$ UTR of cirA mRNAs as well as participate in RNaseE recruitment to induce the rapid degradation of target mRNAs (Ikeda et al., 2011; Salvail et al., 2013). This indicates a novel role and mechanisms of action for this sRNA, and these are extensively discussed in a recent review by Ng Kwan Lim et al. (2021).

Whether Hfq was the sole RNA chaperone, which was answered using a Grad-seq, technology first used in Salmonella (Smirnov et al., 2016). This enabled the discovery of several sRNAs such as RaiZ, associated with ProQ RNA-binding protein. The authors demonstrated that RaiZ represses the expression of the histone-like protein $\mathrm{HU}-\alpha$ and that ProQ acts as a chaperone in RaiZ transcription stabilization rather than facilitating base-pairing. RIL-seq then enabled a redefinition of the interactomes of $\mathrm{Hfq}$ and ProQ, revealing their overlapping and competing roles (Melamed et al., 2020). In other Gramnegative bacteria such as Legionella and meningococcus, identification and exploration of ProQ and ProQ-like proteins has demonstrated that $\mathrm{Hfq}$ is not the only player in the RNA-binding hub (Attaiech et al., 2016; Bauriedl et al., 2020).

Conversely, the need for the RNA chaperone to enhance sRNA-mRNA interactions seems marginal in Gram-positive bacteria, as no $\mathrm{Hfq}$ homologs exist in streptococci or lactobacilli (Mellin and Cossart, 2012). Investigations into Hfq functions in S. aureus and Bacillus subtilis using deleted strains did not result in any significant phenotypes, and several Hfq-independent sRNAs have now been described (Bohn et al., 2007; Rochat et al., 2015). However, studies in L. monocytogenes did reveal a functional albeit sometimes minor role for Hfq in sRNA-mediated regulation or tolerance to stress and virulence (Christiansen et al., 2004; Mandin et al., 2007). Co-immunoprecipitation coupled to enzymatic RNA sequencing produced the first evidence of interaction between Hfq and three sRNAs (Christiansen et al., 2006). Among these, LhtA regulates the translation and degradation of its mRNA targets through an Hfq-dependent antisense mechanism (Nielsen et al., 2010, 2011). In contrast, the multicopy sRNA LhrC identified in the same screen (Christiansen et al., 2006) does not require Hfq to stabilize its interaction with $\operatorname{lap} B$, its target mRNA (Sievers et al., 2014). Together, these results indicate a controversial and probably dispensable role for $\mathrm{Hfq}$ in post-transcriptional control of gene expression in several Gram-positive species. This points to major differences in sRNA-mediated regulation between Gram-negative and Gram-positive bacteria, or perhaps to the existence of other RNA chaperones (Jørgensen et al., 2020) yet to be discovered. 


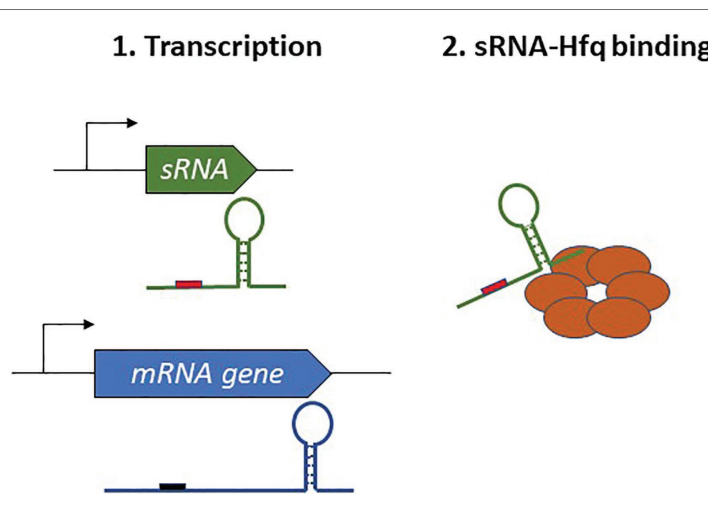

3. sRNA-mRNA duplex formation

4. Effects

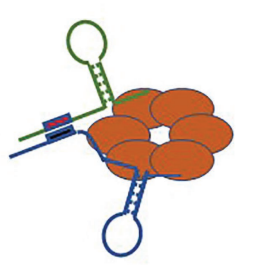

\author{
Modification of \\ accessibility to RBS \\ mRNA degradation \\ or protection
}

FIGURE 1 | Schematic overview of Hfq-dependent small regulatory RNA (sRNA) complex formation and the resulting effects on target mRNAs.

\section{Sequestration of Proteins by sRNAs}

Small regulatory RNAs do not necessarily anneal to the RNA chaperone to enhance target recognition. They can bind proteins to inhibit their action by mimicking the structures of their target mRNAs, although examples of this are limited, and mostly restricted to Gram-negative bacteria. For instance, the homodimeric RNA-binding protein CsrA is sequestered by CsrB and CsrC sRNAs, which antagonize its activity (Liu et al., 1997; Weilbacher et al., 2003). This CsrA carbon storage regulator normally represses gene expression by direct binding with the translation initiation region of its mRNA targets, and only a few examples of gene activation have been reported (Pourciau et al., 2020). This sRNA is associated with posttranscriptional control of its targets rather than the transcriptional control usually described for TFs, and it affects translation initiation, RNA stabilization, and transcription termination. For optimal sequestration of the protein, CsrB and CsrC sRNAs contain multiple CsrA-binding sites, with $\sim 18$ in CsrB. That sRNA harbors repeated sequence elements, including a GGA motif present in the loop of hairpin structures or in singlestranded regions (Romeo, 1998). These GGA seeds decoy the CsrA target motifs usually present near the SD sequence of target sRNAs. Similar decoy seed regions are found in several CsrB homologs in various bacterial species (Babitzke and Romeo, 2007; Janssen et al., 2018; Müller et al., 2019; Sonnleitner et al., 2020). sRNAs in the CsrB family have an impact on the CsrA regulon and on various physiological functions such as biofilm formation, host-microbe interaction, and virulence (Vakulskas et al., 2015). Their expression relies on the BarA/ UvrY two-component system, increasing under nutrient limitation or cellular stress, and decreasing through RNA degradation in the presence of the preferred carbon source (Pourciau et al., 2020). In addition, a reciprocal regulation was also revealed, as free CsrA is mandatory for CsrB/C synthesis. Unusually, sRNAs in the Csr family have short halflives, allowing for the rapid adjustment of CsrA activity in response to environmental cues. Ultimately, it has been shown that CrsB homologs do not necessarily sequester CsrA. In $P$. aeruginosa, CsrZ antagonizes $\mathrm{Hfq}$, resulting in differential carbapenem susceptibility during growth on different carbon sources (Sonnleitner et al., 2020). More roles were reported for CsrA in B. subtilis, where it allows the formation of complexes between the sRNA and its mRNA target, therefore, working as an Hfq-like or ProQ-like RNA chaperone (Müller et al., 2019). Additionally, some sRNAs belong to type III toxin-antitoxin (TA) systems in which the regulatory RNA binds and sequesters its cognate toxin (Brantl and Jahn, 2015).

\section{CLASSIFICATION OF BASE-PAIRING ACTING SRNAS ACCORDING TO THEIR ORIGINS AND MECHANISMS OF ACTION}

Base-pairing sRNAs are expressed from a large variety of loci, and they can be generated from the genome or plasmids (Tomizawa et al., 1981). Within the genome, they are transcribed from both the core genome and accessory genomes such as pathogenicity islands (Pichon and Felden, 2005), and either antisense to their target or trans-encoded from a locus distant to their cognate targets.

\section{Antisense-Encoded sRNAs and Their Mechanisms of Action}

Antisense-encoded sRNAs (asRNAs), also called cis-encoded antisense RNAs, are encoded on the DNA strand opposite to their mRNA target. They share extensive and perfect complementary with part of their mRNA target, allowing efficient regulation without usually requiring the RNA chaperone. They were originally discovered in plasmids and other genetic mobile elements such as phages and transposons (Tomizawa et al., 1981; Brantl, 2002), but we now know that they are present throughout in the genome. For some asRNAs, additional targets transcribed from distant loci have been reported, indicating that they can also act as trans-encoded sRNAs. asRNAs have a large range of lengths, from $\sim 50$ to several thousand nucleotides. They can be transcribed from a DNA strand whose coordinates are within the coding region (CDS) of the opposite strand, overlapping with a CDS (at the $5^{\prime}$ or 3' UTR), or in the case of the very long RNAs (lasRNAs), antisense to a complete operon (Dühring et al., 2006; 
Figures 2A-D). Their identification is challenging, as wide antisense transcription was reported in several pathogens including $S$. aureus, making it difficult to distinguish between "true" asRNAs (having their own promoters) and transcriptional noise (Lasa et al., 2011). Of the thousands of asRNAs identified in a single species, only a tiny subset has been functionally characterized. Plasmid-encoded asRNAs are often constitutively expressed and involved in specific biological functions such as plasmid replication, conjugation, post-segregational killing, and transposition (Wagner et al., 2002). Conversely, genomeencoded asRNAs are primarily linked to the functions of the protein encoded from the opposite strand, and their expression is modulated under specific conditions (Brantl, 2007). Most often, asRNAs are responsible for post-transcriptional regulation and they exhibit a large array of mechanisms of actions that include transcription attenuation or inhibition, modification of mRNA decay, RNA pseudoknot formation, and primer maturation inhibition (Brantl, 2007; Figure 3). In a few cases, activating mechanisms have been reported. Similar mechanisms of action have also been described for trans-encoded sRNAs. We will not discuss the inhibition of primer maturation here, as this mechanism of action is mostly restricted to plasmid replication and is not generally applicable to most asRNAs or trans-encoded sRNAs.

\section{Transcription Attenuation}

Transcription attenuation occurs when a termination structure is formed in the target mRNA after asRNA annealing (Figure 3A). This was first observed as a means to control copy numbers in staphylococcal and streptococcal plasmids (Novick et al., 1989; Brantl et al., 1993; Brantl, 2002). In these bacteria, rep mRNAs can adopt two mutually exclusive conformations depending on the presence or absence of the asRNA. Expression of the asRNA induces a terminating stem-loop that causes the premature termination of rep transcription upstream from the RBS, thereby preventing translation initiation. Conversely, in the absence of the asRNA, the natural conformation of rep mRNA prevents stem-loops from forming. This structure enables the transcription of full-length rep mRNA, permitting translation and therefore plasmid replication. Such a mechanism of action has been reported in the post-transcriptional control of the virulence gene icsA in Shigella flexneri (Giangrossi et al., 2010), as well as in iron transport in the fish pathogen Vibrio anguillarum (Stork et al., 2007). That first study identified RnaG, an asRNA expressed from the opposite strand of iscA. Upon RnaG expression, the formation of a heteroduplex induces the formation of an intrinsic terminator, thus leads to transcription termination (Giangrossi et al., 2010). In the second study, the expression of the asRNA RNA $\beta$ enabled transcription termination within the fatDCBA-angRT transport and siderophore biosynthesis operon, resulting in approximately 17-fold higher expression levels of fatDCBA genes than angRT ones (Stork et al., 2007).

\section{Translation Inhibition}

Translation inhibition is probably the most well-known RNA-mediated mechanism employed to post-transcriptionally regulate gene expression (Figure $3 \mathrm{~B}$ ). Here, the asRNA presents perfect complementarity with the RBS of the mRNA transcribed
A

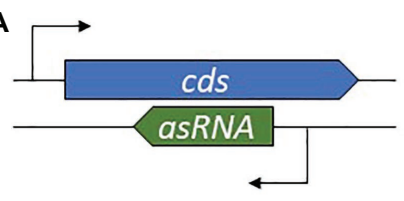

C
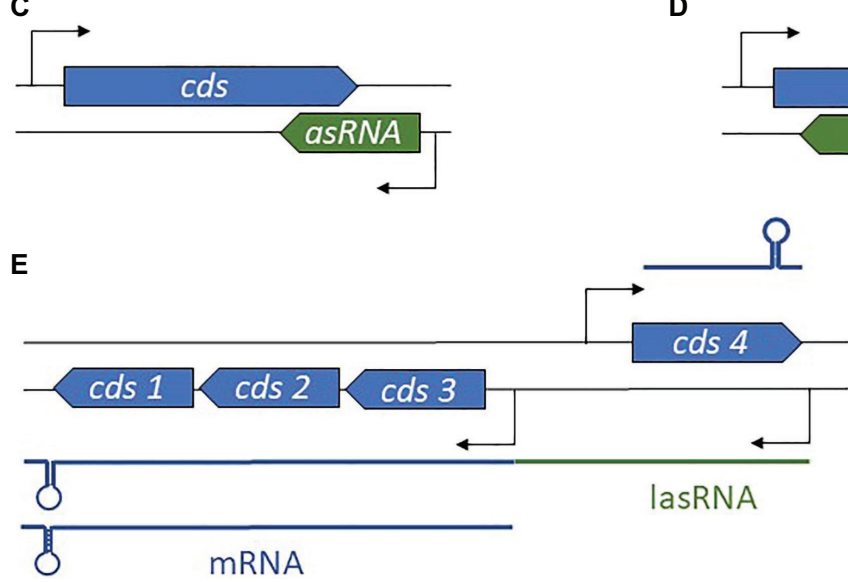

B

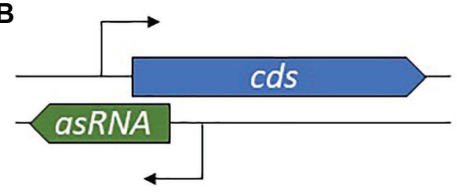

D

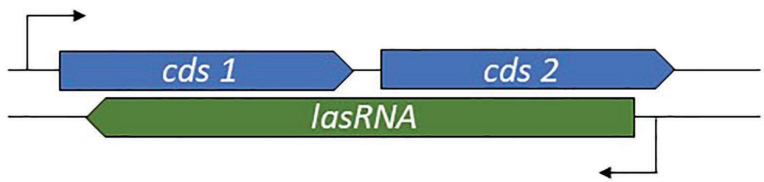

FIGURE 2 | Diversity in antisense RNA (asRNA) genomic locations and lengths. (A) Position of an intragenic asRNA. (B) An asRNA complementary to and overlapping the 5' untranslated region (UTR). (C) An asRNA complementary to and overlapping the 3' UTR. (D) A long asRNA (lasRNA) covers multiple genes. (E) In the concept of the excludon, an lasRNA controls the expression of an mRNA expressed from the opposite strand, and also encodes mRNA. cds, coding sequence. 


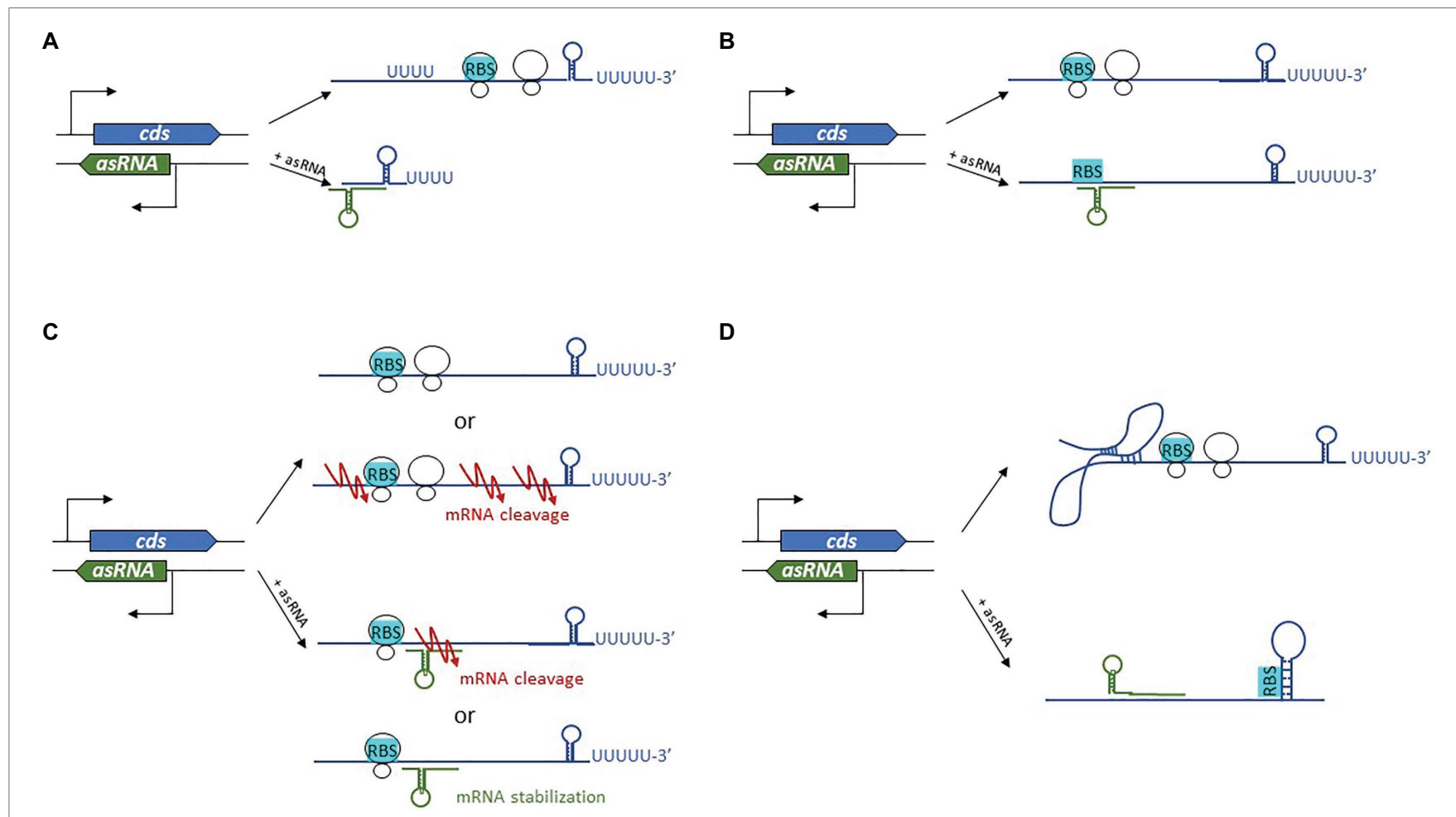

FIGURE 3 | Diverse regulatory mechanisms are employed by cis-encoded antisense RNAs (asRNAs). (A) Premature transcription termination results in transcription attenuation. (B) When ribosomal loading is blocked, translation is inhibited. (C) Modification of mRNA decay after mRNA stabilization or RNase recruitment. (D) RNA pseudoknot formation leads to modified RBS accessibility. cds, coding sequence and RBS, ribosome binding site.

from the opposite strand, so it competes with ribosome loading. Several examples have been described in plasmidic asRNAs, such as RNAII which controls plasmid pLS1 replication by binding the repB RBS (Brantl, 2007). A similar mechanism was reported in FinP, an asRNA which represses the expression of TraJ by blocking ribosomal access to traJ mRNA, inhibiting conjugation. For optimal regulation in this case, the FinO RNA chaperone is necessary to facilitate RNA-RNA duplex formation and to protect FinP against RNaseE-mediated RNA degradation (Arthur et al., 2003).

\section{Modification of mRNA Decay}

The binding of the asRNA to its complementary mRNA target also modifies mRNA decay (Brantl, 2007; Figure 3C). Most often, repression is observed through endoribonuclease cleavage of RNA. Indeed, double-stranded RNAs and the asRNA-mRNA heteroduplex are substrates of RNase III. This enzyme preferentially recognizes long dsRNA segments, which are then cleaved. In S. aureus, genome-wide antisense transcription activity was shown to be coupled with RNase III processing of mRNA/asRNA duplexes (Lasa et al., 2011). Such a mechanism may be involved in the post-transcriptional modulation of mRNA counts, as this duplex formation causes at least $75 \%$ of the mRNAs to be specifically cleaved by RNase III. In the same study, the authors reported similar trends in B. subtilis, Enterococcus faecalis, and L. monocytogenes. RNase $\mathrm{E}$ is another RNase that participates in mRNA decay. A good example is that of the Salmonella asRNA AmgR, expressed from the opposite strand of $m g t C$ (Lee and Groisman, 2010; Figure 4A). During phagocytosis, the PhoPQ two-component system senses low concentrations of $\mathrm{Mg}^{2+}$, leading to signal transduction and the induction of the expression of several genes including the mgtCBR operon (Alix and Blanc-Potard, 2008). In addition, PhoP activates the expression of $\mathrm{AmgR}$, which binds $m g t C$ mRNAs, and favors its degradation via RNase E but not RNase III. In the absence of AmgR, the operon is transcribed, promoting bacterial virulence (Lee and Groisman, 2010). Although, the preferred mode of action is the promotion of RNA degradation, there have also been reports of inhibition of mRNA degradation and therefore of positive posttranscriptional effects of asRNAs (Sesto et al., 2013; Svensson and Sharma, 2016).

In bacterial pathogens, several examples of asRNAs overlapping an RBS have been described, and they go beyond plasmid replication-related functions (Thomason and Storz, 2010; Lejars and Hajnsdorf, 2020). This is the case in Pseudomonas, Salmonella, Shigella, Clostridioides difficile, L. monocytogenes, and $S$. aureus, although precise demonstrations of this mechanism of action are lacking, and it is often linked to transcript abundance variations, as recently reviewed (Lejars and Hajnsdorf, 2020). This indicates that translation inhibition and mRNA decay are often concomitant, as we will see for RNAIII in the next section. 
A

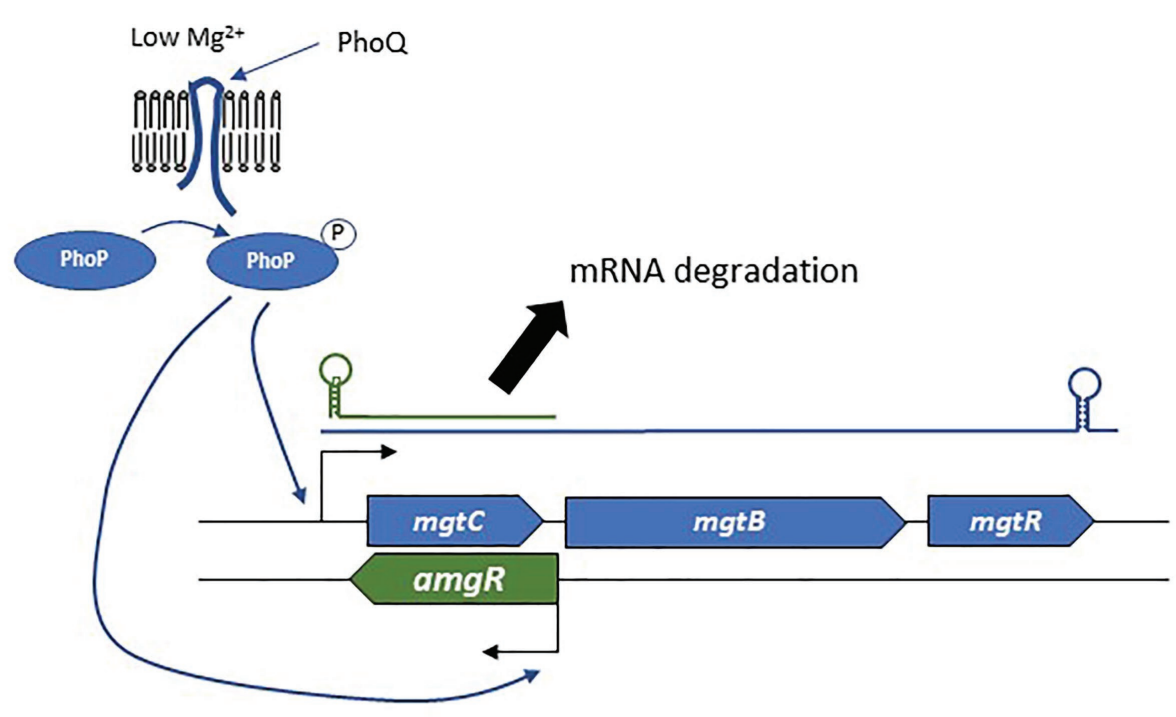

B
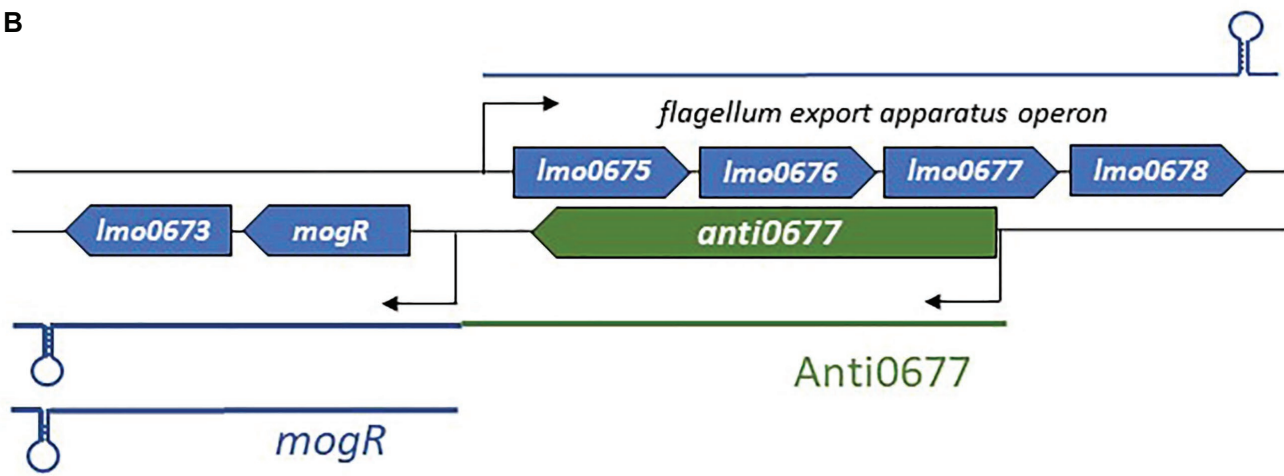

FIGURE 4 | Examples of the mechanism of actions employed by asRNAs. (A) Regulation of the mgtCBR operon and the role of AmgR in degradation of $m g t C$ mRNA. (B) Schematic representation of the flagellum biosynthesis excludon downregulated by the long asRNA Anti0677.

\section{RNA Pseudoknot Formation}

RNA pseudoknot formation can be altered by the presence of asRNAs (Asano and Mizobuchi, 1998a,b). In this case, conformational changes are responsible for regulation as well as for transcription attenuation (Figure 3D), with the translation of rep $Z$ dependent on the formation of a pseudoknot upstream of the RBS. Binding of the asRNA Inc. to repZ mRNA blocks the formation of this pseudoknot and thus prevents translation (Brantl, 2007).

\section{The Excludon}

In addition to the canonical localizations and mechanisms of action, a novel concept in bacterial asRNA-mediated gene regulation has also emerged: the excludon (Sesto et al., 2013; Toledo-Arana and Lasa, 2020). This was first delineated in L. monocytogenes soon after the identification of a group of lasRNAs (Wurtzel et al., 2012). In an excludon, transcription of lasRNAs is initiated from a promoter located on the opposite strand of the CDS (Figure 2E). One interesting feature of the excludon is that transcription continues beyond the overlapping region, also encompassing the coding regions located downstream from the actual asRNA locus. Through this atypical mode of biogenesis, the transcript possesses dual functions, with the 5' antisense regulator of the gene(s) expressed from the opposite strand, while the 3' moiety encodes one or more proteins. Several excludons are reported in L. monocytogenes, and the functions encoded within the locus (i.e., lasRNA and mRNA) are closely related (Sesto et al., 2013). In that pathogen, excludons were shown (or predicted) to be involved in flagellum biosynthesis, a permease-efflux pump, or utilization of carbon sources. As these examples have already been well-described (Sesto et al., 2013), we will just discuss the mechanism of action employed in the biosynthesis of flagella (Figure 4B), extracellular appendages important for cell motility, biofilm formation, and host cell invasion (O'Neil and Marquis, 2006; Lemon et al., 2007). The excludon is composed of four genes 
expressed from the positive strand that encodes the flagellum export apparatus, lmo0675, lmo0676, lmo0677, and lmo0678. Two genes of this operon are encoded divergently, including the $\operatorname{mog} R$ transcriptional regulator of the flagellum export apparatus (Figure 4B). The lasRNA Anti0677 is expressed from a $\sigma^{\mathrm{B}}$-dependent promoter far upstream from $\operatorname{mog} R$ and as an antisense of $l m o 0677$. When bacteria are not subjected to stress, the flagellum export apparatus operon is under the sole control of the transcriptional repressor MogR. Under stress conditions, $\sigma^{\mathrm{B}}$ promotes transcription of Anti0677, leading to an efficient switch-off of the flagellum production through direct antisense inhibition of the operon and increased MogR expression in both $\operatorname{mog} R$ mRNAs and Anti0667 lasRNAs. Recently, a similar "noncontiguous operon" organization leading to transcriptional interference coupled with endoribonuclease-mediated cleavage was reported in S. aureus (Sáenz-Lahoya et al., 2019).

\section{sRNAs in Type I Toxin-Antitoxin Systems}

Several asRNAs belong to type I TA systems. Type I TA modules are composed of a stable toxic peptide and a labile asRNA that inhibits toxin expression, although the existence of divergently expressed genes leading to the expression of a trans-encoded sRNA has also been reported (Brantl and Jahn, 2015). Initially discovered on plasmids, where their role in post-segregational killing prevents plasmid loss during cell division, overexpression of these systems induces small membrane-damaging peptides, which leads to cell death, global translation inhibition, and commitment to persistence. Their mechanisms of action often rely on a perfect complementarity between the RNA antitoxin and the mRNA target, and are associated with translation inhibition and dsRNA-degradation of the heteroduplex through RNase III recruitment (Wen and Fozo, 2014). However, several new features have also been reported, particularly in $S$. aureus.

The type I TA SprA/SprA $\mathrm{AS}_{\mathrm{AS}}$ system identified in a pathogenicity island (Pichon and Felden, 2005), exemplified the fact that an asRNA regulates in trans the translation of its cognate antitoxin (Sayed et al., 2012). Here, the two genes overlap at their 3' ends, suggesting that the putative mechanism of action is not the annealing of the RNA antitoxin onto the RBS. Structural probing of SprA1 RNAs showed the presence of two pseudoknots and a 5 ' stem-loop that unfavored RBS accessibility. Upon $\operatorname{SprA1}_{\mathrm{AS}}$ binding, an internal RNA pseudoknot of SprA1 unfolds and forms a helix with $\mathrm{SprA1}_{\mathrm{AS}}$. Surprisingly, gel retardation assays and mutational analysis revealed that by imperfect base-pairing, the non-overlapping region of $\operatorname{SprAl}_{\mathrm{AS}}$ binds the antitoxin to the RBS, preventing ribosome loading and translation. Therefore, in a trans-encoded manner, the cis-encoded asRNA $\operatorname{SprAl}_{\mathrm{AS}}$ negatively regulates the translation of its cognate antitoxin. A similar cis-trans mechanism of action was also reported in the SprA2/SprA2 $2_{\text {AS }}$ type I TA module (Germain-Amiot et al., 2019).

The SprG/F TA module is another intriguing example of the TA system, in which, the RNA antitoxin can acts in trans and exert several functions. This system was originally characterized by its perfect base complementarity between the 3 ' end of each RNA and for not competing with ribosome loading (Pinel-Marie et al., 2014). However, the authors showed that this was sufficient to destabilize mRNA and toxic peptide levels, even if the mechanism was not precisely defined. In a more recent study, SprF1 was demonstrated to have a novel trans-effect on ribosomes and polysomes (Pinel-Marie et al., 2021). A purine-rich sequence in the antitoxin is responsible for binding ribosomes, which results in global translation initiation interference and increased tolerance to antibiotics, thereby enabling the formation of persister cells. This new finding suggests that type I antitoxin RNA functions are not restricted to regulation of their cognate toxins.

\section{Trans-Encoded sRNAs}

Trans-encoded sRNAs are associated with intergenic regions and are relatively easy to identify experimentally or via predictive tools, since they have distinctive features including a consensus promoter region and $\mathrm{U}$-tract following inverted repeated sequences (intrinsic terminator). Their biogenesis occurs at a locus distant from their targets, so their seed sequences share partial complementarity with them. These sRNAs thus usually regulate more than one mRNA through some of the mechanisms detailed for asRNAs. This partial complementarity, which could represent an apparent weakness, is in the most cases circumvented with the help of RNA chaperones. These sRNAs transcribed from intergenic regions represent the largest set of functionally characterized molecules in the bacterial kingdom. They are expressed under specific conditions to fine-tune gene expression and are highly structured, which may contribute to their increased stability (Waters and Storz, 2009). Typically, they have one or more stem-loops, some of which have cytosinerich motifs that favor interaction with the RBSs of their targets (Geissmann et al., 2009). As mentioned above, trans-encoded sRNAs are involved in a large set of functions, with repression the most common outcome, although examples of activation have also been reported.

\section{Trans-Encoded sRNA Activators}

While considered marginal, there are growing examples of trans-encoded sRNAs that permit increased translation and/ or mRNA stabilization (Figure 5A). Activation of sRNA basepairing is typically associated with the $5^{\prime}$ UTR, although targeting of the coding sequence is also possible (Papenfort and Vanderpool, 2015).

Activation via the 5' UTR involves two mechanisms of action. The first is an anti-antisense mechanism that induces structural modifications to enable the unfolding of an intrinsic structure that inhibits translation. This leads to the release of the occluded RBS, thus enhanced ribosomal access. This has been observed with RNAIII in S. aureus (Morfeldt et al., 1995), further discussed below, as well as with Rli27 in L. monocytogenes (Quereda et al., 2014). Rli27 is involved in cell-wall formation during a pathogen's intracellular lifestyle. It activates the cell wall-encoding protein Lmo0514 via binding of its 5' UTR, thus unmasking the RBS and promoting Lmo0514 production inside eukaryotic cells. The second mechanism of $5^{\prime}$ UTR-activation is mRNA stabilization, an even a less-described phenomenon in which sRNA target-binding protects it from 


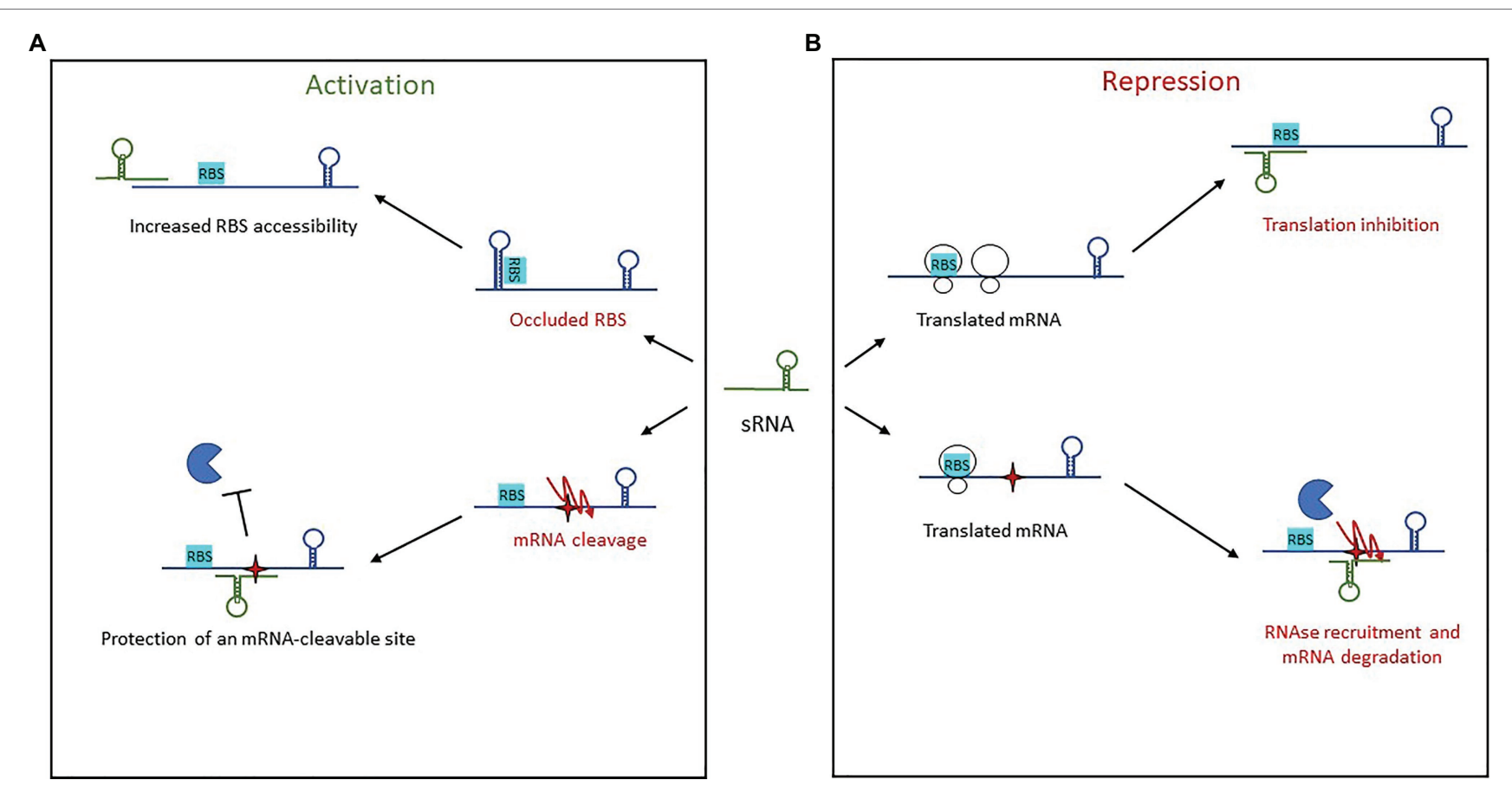

FIGURE 5 | Mechanisms of action used by trans-encoded sRNAs. (A) In post-transcriptional activation, sRNA binding of an mRNA target results in either increased RBS accessibility or protection of an mRNA-cleavable site. (B) Repression of gene expression by trans-encoded sRNAs occurs when the sRNA binds an mRNA target, resulting either in translation inhibition by preventing ribosome loading or else recruitment of an RNase for mRNA degradation.

RNases and therefore from cleavage. This is seen with RydC in Salmonella (Fröhlich et al., 2013). There, RydC adopts a pseudoknot structure at its 5 ' end that contains a seed sequence involved in recognizing a 5' UTR located far upstream from the RBS of $c f a$ mRNA, which encodes CFA synthase. This seed pairing activates Cfa expression by mRNA stabilization through the mRNA cleavage protection provided by RNase E. In Clostridium perfringens, another mechanism of action was reported for the stabilization of the mRNA colA, which encodes collagenase toxin (Obana et al., 2010). In this pathogen, the 3' region of VR-RNA binds colA to mediate cleavage of the mRNA $78 \mathrm{nt}$ upstream the A of initiation codon, resulting in the release of a more stable mRNA.

Other sRNAs activate translation by base-pairing with the coding sequence. In E. coli and Salmonella, the sRNA SgrS involved in sugar homeostasis displays several distinctive features (Papenfort et al., 2013). Like RNAIII, it has dual functions, acting both as a trans-encoded sRNA as well as encoding the small protein SgrT. Among the known targets of SgrS is the second gene of the bicistronic operon pldB-yigL, which is under its positive control and encodes a phosphatase. Under normal conditions, the transcript is processed by RNase E, resulting in yigL transcript level adjustments. When the concentration of phosphorylated sugars increases, regulation is needed to avoid cell toxicity, so SgrS is expressed. It binds the coding sequence to stabilize the yigL transcript by masking a cleavage site recognized by RNase E, thereby preventing its degradation. The increased phosphatase activity lowers sugar phosphate levels and causes the excretion of non-phosphorylated sugars. At the same time, SgrS effectively controls sugar phosphate levels by repressing the expression of three other targets involved in sugar transport, once again demonstrating the versatility of sRNAs as regulators.

\section{Trans-Encoded sRNA Repressors}

Repression by trans-encoded sRNAs involves transcription attenuation, translation repression, and mRNA degradation (Figure 5B). Regulatory signals are often contained within the 5' UTR of target mRNAs. The most common mechanism of action in this group is the repression of translation initiation, with sRNAs binding the RBS to prevent loading by the $30 \mathrm{~S}$ ribosomal subunit. This binding sometimes encompasses the AUG codon, although any interaction surrounding the RBS and AUG up to five codons into the coding sequence is inhibitory (Hüttenhofer and Noller, 1994; Bouvier et al., 2008). Several seed regions/sequence patterns have been described for these trans-encoded sRNAs, and the association of singlestranded RNAs to form heteroduplexes is not the only one. The patterns usually reflect the structural shape of RNAs and include several hairpin loops that require additional features. For instance, "kissing complexes" (loop-loop interactions between sRNAs and mRNAs) can occur when GC-rich sequences present in the sRNA loop associate with the RBS of their target (Lioliou et al., 2010).

To facilitate complex formation, sRNAs (and sometimes mRNAs) have to unfold to generate double-stranded heteroduplexes, which are thermodynamically favorable. C-rich conserved sequences were identified in stem-loops and shown 
to be involved in the recognition of G-rich sequences such as the RBSs of mRNA targets. This was first proved in E. coli for the repression of fhlA by OxyS (Altuvia et al., 1998), then later on in multiple pathogens including L. monocytogenes, Salmonella, H. pylori, V. cholerae, and S. aureus (Papenfort et al., 2008, 2015; Geissmann et al., 2009; Pernitzsch et al., 2014; Sievers et al., 2014). In S. aureus, bioinformatic and phylogenetic analyses were used to identify a conserved unpaired UCCC motif present in the apical loop of several sRNAs, and this was interpreted to be the potential signature of Hfq-independent sRNAs in Gram-positive bacteria (Geissmann et al., 2009; Jørgensen et al., 2020). The role of this motif in the repression of translation was demonstrated for the sRNA RsaE (Geissmann et al., 2009). In L. monocytogenes, LhrC sRNAs contain three redundant CU-rich motifs, with one in a stem-loop, another on a single-strand region, and the last occurring in the terminator (Sievers et al., 2014). These sites are important for the translational repression of LapB at the RBS, and another study showed that LhrC translationally represses OppA via RBS binding of two of the three CU-rich motifs (Sievers et al., 2015). However, there are also examples of sRNAs blocking translation by masking the RBS with seed sequences that do not exhibit strong C-rich motifs. In Salmonella, IsrM, the sRNA involved in virulence, represses the expression of hilE and sopA mRNAs using two different seeds, which seem to have random C-distributions although they still sequester the RBS (Gong et al., 2011). The presence of two seeds in IsrM indicates that sRNAs can have several regulatory domains. In $S$. aureus, the multifaceted sRNA RsaI expressed under glucose-limited conditions displays similar properties, with two distinct regulatory domains (Bronesky et al., 2019). The first is a typical unpaired CU-rich sequence that base pairs with the RBSs of most of the identified mRNA targets (sugar uptake and metabolism). The second is a G-rich sequence that binds the CU-rich tracts of other sRNAs such as RsaD, RsaG, RsaH, and RsaE, indicating the potential existence of other mechanisms of actions for controlling sRNA functions.

Apart from the ribosome binding site, other target regions do exist. For instance, sRNAs can bind their mRNA targets upstream from the RBS, within the coding region or at the 3' UTR. The Salmonella sRNA GcvB contains the GU-rich sequence that interacts with the CA-rich sequences of its target mRNAs (Sharma et al., 2007). For at least one target, gltl mRNA, the sRNA specifically recognizes a sequence far upstream from the RBS $(\sim 50 \mathrm{nt})$ that actually acts as a translational enhancer sequence. Still in Salmonella, examples of sRNAs binding coding sequences several nucleotides downstream from the RBS were also reported. In that bacterium, MicC sRNAs repress ompD mRNAs via binding to codons 23-26, which is sufficient for repression (Pfeiffer et al., 2009). By doing so, MicC increases RNase E-dependent ompD mRNA decay rather than repressing translation. Interestingly, the SdsR sRNA also represses ompD using a similar mechanism between the 15th and 26th codons (Fröhlich et al., 2012).

The sRNA can also bind the 3' UTR of an mRNA to modulate its expression. For instance, $S$. aureus RsaI binds the 3' UTR of the mRNA icaR, which encodes a transcriptional repressor of exopolysaccharide production (Bronesky et al., 2019). Although the mechanism of action is yet not understood, this binding contributes to the translational repression of IcaR either by preventing the action of trans-acting activators (proteins or RNAs) or by indirectly stabilizing the interaction between the 5' and 3' UTRs of icaR mRNAs, known to sequester the RBS.

Along with translation inhibition, sRNA-mediated regulation often involves degradation by RNases. Untranslated mRNAs are subjected to RNA degradation since the absence of polysomes does not protect RNAs from RNAses (Deana and Belasco, 2005). Furthermore, the sRNA-mRNA duplex can be used to recruit RNaseE as the means to control RNA decay (Morita et al., 2005; Bandyra et al., 2012). Some sRNAs are then co-degraded with their targets, some are recycled like enzymes, and the fate of the others depends on their molecular target (Massé et al., 2003; Feng et al., 2015). In addition to RNase $\mathrm{E}$, roles for RNase III and RNase $\mathrm{Z}$ were also reported in target RNA degradation (Dutta and Srivastava, 2018).

Altogether, study of trans-encoded sRNAs reveals that they can act anywhere on their mRNA targets and that any parts of their sequences can have regulatory functions, implying unlimited possibilities for their mechanisms of action.

\section{Cis-Acting Regulatory Elements of mRNAs: Riboswitches, Thermosensors, and $\mathrm{T}$ Boxes}

Although not considered to be sRNAs, riboswitches are pivotal players in RNA-mediated regulation of gene expression, and as we will see later, their extraordinary versatility lets them closely link with sRNAs. Riboswitches are natural aptamers usually identified in the 5' UTR of some mRNAs in both Gram-positive and Gram-negative bacteria. They are cis-acting elements regulating at the transcriptional and/ or translational levels the expression of their downstream genes. To do this, they sense by physical interaction metabolite variations, then modify their secondary structures to form two mutually exclusive RNA conformations (Mironov et al., 2002; Winkler et al., 2002; McDaniel et al., 2003; Nudler, 2006). They contain two distinct functional domains: a metabolite-sensing domain, and an expression platform. Ligand binding induces conformational changes that lead to transcription termination or inhibition of translation initiation. One interesting feature of riboswitches is their conserved sensing domain and the variability of their expression platform. This is the case for the riboswitch that senses thiamine pyrophosphate (TPP): its sensing domain specifically and selectively binds TPP, while its expression platform induces transcription termination in Gram-positive bacteria and suppresses translation initiation in Gram-negative bacteria (Serganov et al., 2004; Nudler, 2006). Another specific feature of riboswitches is their ability to bind ligands without the need to establish Watson-Crick base pairs. The riboswitch folds into a very specific configuration that allows target metabolite recognition and sequestration due to the hydrogen bonds of RNA bases and ribose sugars. Riboswitches are 
widespread and diverse, as a plethora of effectors have been identified (TPP, SAM, FMN, sugars, divalent ions, etc.). Usually, they control the expression of genes that have functional links with their effector.

The canonical description of the riboswitch mode of action was overturned by the discovery that they can act as RNA thermometers and $\mathrm{pH}$ meters, thus they can be active without necessarily requiring metabolite sensing. RNA thermometers generally fold in a temperature-dependent manner to generate alternative conformations that affect translation (Kortmann and Narberhaus, 2012). The first example of an RNA thermometer was identified in the pathogen L. monocytognes (Johansson et al., 2002). In this study, the authors showed that the switch into virulence orchestrated by PrfA, the master regulator of virulence, is actually dependent on a conformational change of the $5^{\prime}$ UTR of its cognate mRNA. At $30^{\circ} \mathrm{C}$, the $\operatorname{prfA} 5^{\prime}$ UTR adopts a secondary structure that masks the RBS, acting as a translation repressor. At $37^{\circ} \mathrm{C}$, the energy provided by the increased temperature is sufficient to cause a structural switch that enables translation of the TF. Additional thermometers are found in many pathogens such as Salmonella Typhi and S. aureus (Hussein et al., 2019; Brewer et al., 2021; Catalan-Moreno et al., 2021), and have been extensively reviewed (Loh et al., 2018).

The first 5' UTR element to be identified in the late 1990s was the T-box, which controls the expression of genes involved in amino acid biosynthesis or use. They are typically upstream aminoacyl-tRNA synthetase transcripts, are widely distributed in Gram-positive bacteria, and they respond to the accumulation of uncharged tRNAs when cognate amino acid concentrations are too low. Contrary to metabolite-sensing riboswitches, T-boxes bind uncharged tRNAs by base-pairing with their anticodons and with the acceptor-end T/D loops to stabilize an anti-terminator element, allowing synthesis of full-length mRNA. In Clostridium acetobutylicum (André et al., 2008) and later in L. monocytogenes (Mellin et al., 2013), exploration of T-box riboswitches led to the discovery of a novel mechanism of action, with cis elements involved in antisense RNA control located downstream (these turned out to be SAM riboswitches) and on the opposite strand of the gene. Other unexpected riboswitch mechanisms of action is reviewed here (Mellin and Cossart, 2015).

\section{UNCONVENTIONAL REGULATORY RNA BIOGENESIS AND FUNCTIONS}

The term "sRNA" was often restricted to those species transcribed from intergenic regions, or as antisense to a coding sequence. Ongoing efforts to identify novel sRNAs and to decipher their mechanisms of action has demonstrated that they harbor an even broader than expected variety of structural traits, biological functions (and even sometimes dual functions), and modes of biogenesis. For instance, studies have shown that RNA regulators are also produced from 5' to 3' UTRs (Miyakoshi et al., 2015b; Heidrich et al., 2017; Carrier et al., 2018).

\section{The Fascinating Case of RNAIII in Staphylococcus aureus}

RNAIII is one of the best-characterized sRNAs in pathogens and probably even in bacteria. It was first described in 1993, when it was defined as the intracellular effector of the Agr system (Novick et al., 1993). It is one of the most representative examples of the sRNA with distinctive futures. RNAIII is a 514-nt long dual-function sRNA whose expression is regulated by growth phase and cell density through QS. RNAIII acts at a posttranscriptional level by using antisense mechanisms, which lead to translation inhibition and/or modification of target RNA stability (Figure 6). RNAIII positively or negatively regulates a large number of targets through various mechanisms, and has a complex structure with 14 stem-loops (Benito et al., 2000) of which three contain C-rich sequences. These three hairpins, H7, H13, and $\mathrm{H} 14$, are involved in translation repression, preventing ribosomes from loading onto target RBSs. The first stem-loop (H1) is required for RNAIII stability, while $\mathrm{H} 14$ acts as an intrinsic transcription terminator. $\mathrm{H} 3, \mathrm{H} 4$, and $\mathrm{H} 5$ are responsible for the definition of this sRNA as dual-function, another sRNA subgroup which has been extensively reviewed (Gimpel and Brantl, 2017; Raina et al., 2018). These three stem-loops encode $\delta$-hemolysin (Hld), which is a toxin made of 26 amino acids arranged into an $\alpha$-helix structure, and which permeabilizes host cells (Figure 6). Interestingly, there is not a perfect transcriptiontranslation coupling between hld mRNA biogenesis and translation of the Hld peptide. Although the cause for this is not completely understood, it was reported that deletion of the 3' end of RNAIII abolishes this delay, suggesting either that a third party is involved (Balaban and Novick, 1995) or that the 5' and 3' regions of RNAIII are (or serve as) cis-regulatory elements. RNAIII is under the positive transcriptional control of AgrA and accumulates in bacteria over the course of the growth phase, reaching its maximal transcript levels during the post-exponential phase (Dunman et al., 2001). With its versatile effects, RNAIII orchestrates the transition between colonization and infection by repressing early virulence genes and activating other virulence factors (Table 1).

\section{RNAIII Target Repression}

RNAIII represses the expression of several genes involved in virulence (adhesion or immune evasion), including Rot TF (Table 1). The mechanism of action is always translation repression, with RBS binding in order to prevent ribosome loading and translation initiation. In most cases, duplex formation is followed by rapid degradation of the mRNA target through the recruitment of RNase III (Bronesky et al., 2016), although the mechanism differs for the regulation of Sbi and perhaps also for LytM (Boisset et al., 2007; Chabelskaya et al., 2014).

Repression of Spa involves the 3' end domain of RNAIII (Huntzinger et al., 2005). Spa is one of the major surface proteins involved in host interactions as well as virulence (Foster, 2005). Based on sequence complementary, the deletion of RNAIII's H13 stem-loop abolishes regulation by RNAIII. This repressive hairpin sequesters the spa RBS to prevent translation initiation, although efficient repression requires RNase III. A similar repression mechanism involving $\mathrm{H} 13$ and 


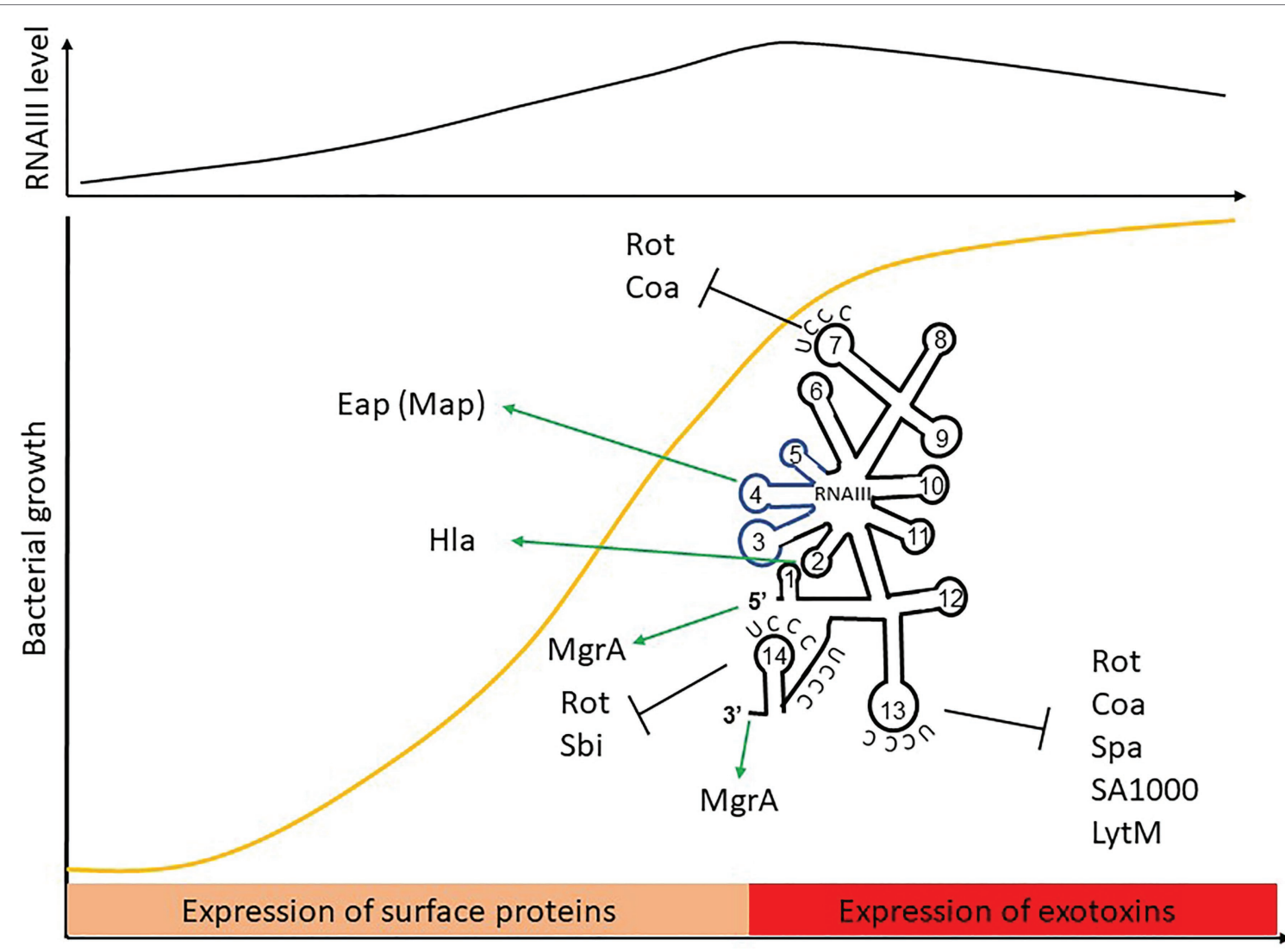

FIGURE 6 | The RNAlll paradigm: activation and repression of gene expression is carried out by a dual-function sRNA encoding $\delta$-hemolysin. The $h l d$ coding sequence is blue.

RNase III was reported for SA1000, which encodes a fibrinogenbinding protein (Boisset et al., 2007). Repression of Rot, the repressor of toxin Rot requires hairpins H7, H13, and H14, who form kissing complexes to permit translation repression and RNase III cleavage (Boisset et al., 2007). To do this, H7 and $\mathrm{H} 13$ enable the formation of a loop-loop interaction with the 5' UTR of rot, while H14 is involved in a loop-loop interaction with the mRNA RBS. Two loop-loop interactions are needed for efficient translation inhibition, and binding of RNAIII with rot induces a specific signature for RNase III cleavage. Rot is known to inhibit the production of several exotoxins after their transcription as well as to enhance Spa expression. Therefore, RNAIII inhibition of Rot indirectly promotes exotoxin expression and represses surface protein production.

As with Rot, RNAIII repression of Coa involves two stemloops (H7 and H13), although the structural conformations differ between these examples (Chevalier et al., 2010). In this case, H13 sequesters the coa RBS through canonical imperfect double-strand base-pairing and this is sufficient to block the formation of ribosomal initiation complexes. Additionally, H7 forms a loop-loop interaction with the 3' end of coa, and both RNAIII-coa complexes serve as templates for RNase III.

RNAIII regulation of LytM is less documented. While bioinformatic predictions suggest that stem-loop H13 is involved
(Boisset et al., 2007), and it is known that the lytM RBS is an RNAIII target (Chunhua et al., 2012), the precise mechanism of action and the putative involvement of RNase have not yet been determined.

Sbi is another target repressed by RNAIII (Chabelskaya et al., 2014), and it is negatively regulated by SprD sRNAs (Chabelskaya et al., 2010). Sbi protein participates in antiopsonization effects by binding immunoglobulins (Foster, 2005). Three distant RNAIII domains interact with sbi mRNAs, with two annealing regions located within the sbi coding region and one on the RBS to block translation initiation. Since RNAIII and SprD are not expressed at the same time, these studies highlight a cooperative role of these two sRNAs to precisely control Sbi expression suggesting the presence of complex sRNA control networks in bacteria.

\section{RNAll Activation of Gene Expression}

In addition to its inhibitory roles, RNAIII can also directly activate several targets. This is true in the case of Hla, whose expression is reduced in a mutant lacking RNAIII (Morfeldt et al., 1995). RNAIII binds hla mRNAs to prevent the formation of a structure that would sequester the RBS, thereby promoting RBS accessibility and translation. Unlike the mechanism involving repression, here the $5^{\prime}$ end ( $\mathrm{H} 2$ in RNAIII) is required for base-pairing with hla. Map (also known as Eap) is another 
target that is stimulated by RNAIII (Liu et al., 2011). To activate Map expression, RNAIII binds the 5' UTR of map using its hairpin $\mathrm{H} 4$, which suggests a structural modification that enables ribosomal loading, although the mechanism of action has not yet been unraveled. RNAIII was also shown to positively regulate MgrA (Gupta et al., 2015), the TF which inhibits surface proteins, autolysis, and biofilm formation, as well as promoting capsule synthesis (Bronesky et al., 2016). Interestingly, MgrA also activates the expression of Agr and thus indirectly RNAIII (Ingavale et al., 2005). RNAIII stabilizes $m g r A$ RNAs by doublestrand base-pairing using both its $5^{\prime}$ and $3^{\prime}$ ends (Bronesky et al., 2016), with each end interacting simultaneously with the 5' UTR of mgra mRNA to allow mRNA stabilization and translation.

RNAIII thus differs from the conventional dogma about sRNAs in many ways. It contains a coding sequence, and is therefore considered as a dual-function sRNA. It is longer than most sRNAs, and has a complex structure containing several hairpins, which are crucial for gene repression. Its gene repression mechanism involves translation initiation control and is often associated with RNase III cleavage. The $5^{\prime}$ end is thought to be involved in gene activation via mRNA stabilization and translation activation, while the $3^{\prime}$ end is involved in both activation and the repression mechanisms. The $3^{\prime}$ end is also important for RNAIII's own stability, and therefore may be a key cis element for Hld production. Finally, little is known regarding the role of the other hairpins, suggesting that there may be additional features left to discover.

\section{5' UTR-Derived sRNAs}

5' UTRs are normally considered to be riboswitches, cis-acting elements. The first major evidence of the sRNA produced from a 5' UTR was the cleavage of the two SAM riboswitches SreA and SreB in L. monocytogenes (Loh et al., 2009). In that report, the biogenesis of SreA and that sRNA's mechanism of action were described extensively. During methionine starvation, SAM concentrations are relatively low, leading to the formation of an anti-terminator structure that enables the transcription of the downstream gene. When the concentrations of this ligand increase along with methionine biosynthesis, SAM binds the riboswitch. This allows structural rearrangement and transcription termination, and results in the accumulation of SreA, an sRNA transcript of $229 \mathrm{nts}$ which has trans-acting features. Remarkably, SreA controls the expression of the virulence TF PrfA by binding the 5' UTR of its mRNA, while PrfA exerts a positive control on SreA expression. This shows that some cis-acting regulators can be cleaved to act in trans in response to environmental cues. Another example of a riboswitch-producing trans-acting sRNA was reported in L. monocytogenes (Mellin et al., 2014). The authors showed that in the absence of the ligand, a riboswitch binding vitamin B12 is cleaved and releases Rli55. In turn, Rli55 expression prevents the expression of the eut genes involved in ethanolamine use and whose expression depends on vitamin B12 availability. To do this, Rli55 sequesters EutV, a regulatory protein which binds eut mRNAs to prevent premature termination of transcription. A similar mechanism for regulating eut via protein sequestration was described in
E. faecalis, although there an adenosyl cobalamine-binding riboswitch releases EutX trans-acting sRNAs (DebRoy et al., 2014). In S. aureus, the sRNA Teg49 is derived from the 5' UTR region of TF sarA mRNA (Beaume et al., 2010; Kim et al., 2014). The expression of sarA is under the control of the three promoters P1 through P3, with P3 important for expression during the post-exponential growth phase. Teg49 is transcribed from P3 and is probably the result of RNase III processing. Another study indicated a role of Teg49 in virulence, although the mechanism of action is not clearly understood (Manna et al., 2018).

Based on the first discoveries, 5' UTR-derived sRNAs are probably more present in Gram-positive pathogens. It was proposed that the relative absence of such sRNAs in Gramnegative pathogens is explained by the fact that most sRNAs studies have been designed based on Hfd-binding. This binding usually occurs with the $3^{\prime}$ poly(U) tail of sRNAs located downstream from intrinsic terminators, and these are likely to be absent in 5' UTR-derived sRNAs. Additionally, the need for Hfq-binding was questioned (Carrier et al., 2018). The mystery was solved in P. aeruginosa with a screen that attempted to map transcription termination sites affected by homoserine lactone quorum sensing (Thomason et al., 2019). Term-seq analysis identified RhlS as a novel Hfq-dependent sRNA expressed from the 5' UTR of rhll, an actor in the Rhl two-component system related to quorum sensing. Interestingly, RhlS is not derived from a riboswitch, but is induced when homoserine lactone concentrations increase. RhlS not only controls the translation of its downstream gene ( rhll), but also regulates the translation of $f p v A$ mRNAs transcribed from a distant locus and which encode a siderophore pyoverdine receptor, although the mechanism of action here is still unclear. Finally, recent work on E. coli focusing on the identification of $3^{\prime}$ ends from 5' UTRs revealed the presence of trans-acting sRNA sponges (Adams et al., 2021).

\section{3' UTR Is a Reservoir of Trans-Acting sRNAs}

Expression of 3' UTR-derived sRNAs occurs frequently in bacteria, and the number of examples is growing quickly. Over the past few years, their identification has become easier with the development of high-throughput screenings such as Termseq, RIL-seq, RIP-seq, and CLASH (Dar et al., 2016; Melamed et al., 2016; Hoyos et al., 2020). These sRNAs act in various physiological regulons including amino acid transport and biogenesis. They are categorized into two classes depending on whether they have their own promoters (type I) or if they are produced by mRNA processing (type II; Miyakoshi et al., 2015b). While type I sRNAs seem completely independent of the gene encoded upstream when it comes to biogenesis the functions they regulate, the expression of type II sRNAs depends on the initial mRNA transcription. So far, more type II molecules have been discovered, and most 3' UTR-derived sRNAs have been discovered in Gram-negative bacteria. Post-transcriptional regulation by 3' UTR elements was recently reviewed (Menendez-Gil and Toledo-Arana, 2020). 


\section{Type I 3' UTR-Derived sRNAs}

This type of 3' UTR-derived sRNA contains its own promoter, located either within the coding sequence or immediately downstream. In 2012, Hfq co-immunoprecipitation of transcripts followed by RNA-seq analysis enabled the discovery of novel sRNAs whose RNA sequences mapped with the 3' region of mRNAs (Chao et al., 2012). During this screen, the authors identified DapZ, an 80-nt sRNA transcribed from its own promoter and that overlaps the $\operatorname{dapB} 3$ ' UTR. Although they share the same terminator, their transcription is independent of each other. DapZ modulates the synthesis of ABC transporters of Opp and Dpp by base-pairing with their cognate mRNAs. One interesting feature of DapZ is that it contains a repressing seed sequence (G/U-rich domain) similar to that of GcvB sRNA, a global regulator of amino acid transport and biosynthesis genes, so they recognize the same targets. This indicates that despite being independent, the two sRNAs can have complementary functions.

In $S$. aureus, a search for novel transcripts uncovered an intricate organization in the Newman strain, with an unusual condensed sRNA cluster (Srn_9342 to Srn_9346; Bronsard et al., 2017). Using 5' RACE mapping combined with TEX and polyphosphatase treatments, the authors were able to show that the Srn_9342 transcription start site is located within the coding region of the upstream gene. This was supported by the identification of a putative sigma $\mathrm{B}$ binding site (Mader et al., 2016). Interestingly, Srn_9342 is expressed in two forms having different lengths and sharing the same 5' extremity, although the mechanism of biogenesis of each form and their respective functions remain to be elucidated. In this specific example, two terminators were predicted (Bronsard et al., 2017), with one sharing the upstream coding sequence as occurs in typical type I 3' UTR-derived sRNAs, and the other specific to the long sRNA species, indicating another variation in sRNA biogenesis within this category.

\section{Type II 3' UTR-Derived sRNAs}

This type of sRNA is derived from RNase E cleavage of an mRNA. An example is CpxQ, a $\sim 60$ nt-long transcript generated through cleavage of the 3' UTR of $c p x P$ mRNA and which requires Hfq for optimal maturation as well as protection from further RNA decay (Chao and Vogel, 2016). Both CpxQ sRNAs and $\mathrm{CpxP}$ proteins are involved in inner membrane homeostasis, with the protein acting as a chaperone for misfolded proteins in the periplasm, and the sRNA controlling their expression in the cytosol. Thus, unlike with type I 3' UTR-derived sRNAs, CpxQ synthesis depends on $c p x P$ transcription, and these two elements cooperate to carry out the same function. In $S$. aureus, after cleavage by the double-stranded RNase III, the sRNA $\mathrm{RsaC}$ is released from the $3^{\prime} \mathrm{UTR}$ of the mntABC operon, which encodes the major manganese $\mathrm{ABC}$ transporter (Lalaouna et al., 2019). This sRNA is intriguing, as its length varies between isolates due to the presence of a variable number of repeats within its internal RNA sequence. The 3 ' domain of $\mathrm{RsaC}$ was found to be involved in translational repression of sodA mRNA during manganese starvation, thereby modulating the response to oxidative stress.
The regulatory functions of these 3' UTR-derived sRNAs are often linked to the biological roles of their associated upstream genes (Menendez-Gil and Toledo-Arana, 2020). They therefore autoregulate the expression of their associated genes at the post-transcriptional level, inhibit translation by basepairing, and serve as negative feedback controls (Chao and Vogel, 2016; Miyakoshi et al., 2019; Hoyos et al., 2020; Wang et al., 2020). As the description of this sub-class of sRNAs is relatively new, it is expected that its ranks will increase in the future.

\section{sRNAs Excised/Expressed From Coding Sequences}

While the examples cited above pertain to biogenesis from the 3' UTR or at least from the 3' end of mRNA coding regions, in-depth study of the transcriptomes of E. coli, Enterobacter aerogenes, and Salmonella Typhimurium uncovered the biogenesis of decay-generated noncoding RNAs (decRNAs) from coding regions situated far from mRNA 3' ends (Dar and Sorek, 2018). The authors identified a set of conserved sequences generated through RNase E activity and predicted to interact with the RNA chaperones Hfq and ProQ. A search for transcriptional start sites using 5' RNA-seq mapping uncovered numerous sRNAs transcribed from within coding sequences in several species including Borrelia burgdorferi and Leptospira interrogans (Adams et al., 2017; Zhukova et al., 2017). However, the functions of this novel type of sRNAs remain to be elucidated.

\section{sRNA Processing to Produce Novel sRNAs or Additional Functions}

In S. aureus, Srn_9342 is not the only sRNA transcribed into two forms (Bronsard et al., 2017), and similar properties were observed for both RsaA (Romilly et al., 2014) and RsaE (Schoenfelder et al., 2019). While transcriptional readthrough was just hypothesized for Srn_9342 and RsaA, post-transcriptional modification was actually demonstrated for RsaE. In $S$. epidermidis, RsaE is normally transcribed as a transcript $\sim 110$-nt long, but it can undergo processing to release a transcript of $\sim 80 \mathrm{nt}$ which lacks the $5^{\prime}$ end. Biogenesis of this second form enables the expansion of the original RsaE targetome. The full-length sRNA specifically regulates antiholin-encoding $\operatorname{lrg} A$ mRNA by binding the RBS, preventing ribosome loading, and influencing mRNA levels. Conversely, the processed RsaE interacts with the 5' UTR of $i c a R$ and sucCD mRNAs, which encode the IcaR repressor of biofilm formation and the succinyl-CoA synthetase of the TCA cycle, respectively.

\section{sRNA Sequestration by Other RNAs (Sponge RNAs)}

As for any genes, we expect sRNA genes and transcripts to require fine regulation. Several TFs were identified as regulators of sRNA transcription, but regulation or sequestration of sRNAs by other RNAs is a relatively new topic of investigation. Research into type II 3' UTR-derived sRNAs engendered the concept of bacterial sponge RNAs, which soak up other sRNAs rather than just proteins in 
order to suppress their regulatory functions (Azam and Vanderpool, 2015). The first sponge to be characterized was chb, which sequesters the sRNA ChiX (Figueroa-Bossi et al., 2009). ChiX represses the expression of ChiP, a porin involved in the uptake of chitosugars. In the absence of chitosugars, ChiX represses ChiP since it is not needed. When chitosugars are present, the chBCARFG operon is transcribed, and an intercistronic spacer sequence between $\operatorname{chbB}$ and $\operatorname{chbC}$ acts as a sponge for ChiX, allowing ChiP expression. Later on, a study reported the case of SroC, a type II 3' UTR-derived sRNA that activates up to 26 targets, while repressing 14, an unusually high number of targets (Miyakoshi et al., 2015a). The authors showed that SroC acts as a sponge of GcvB, the sRNA involved in amino-acid metabolism, and the most repressed of the SroC targets. The intriguing feature is that SroC is produced from the gltJKL operon, an mRNA target of GcvB, indicating an elegant cross-talk mechanism. When produced, SroC binds GcvB by base-pairing, allowing the recruitment of RNase $\mathrm{E}$ and subsequent GcvB degradation and derepression of its targetome. In other words, GcvB sequestration permits the indirect activation of most of the 26 targets identified in the screen, indicating that sRNAs can function using mechanisms similar to some TFs that repress other repressors to activate gene expression. In a second study, SroC was shown to sequester another sRNA, MgrR, by binding its seed sequence (Acuña et al., 2016). In addition to this sponge activity, SroC also indirectly regulates the expression of other targets functionally related to the GcvB targetome (Miyakoshi et al., 2015a). Interestingly, GcvB is also controlled by the AgvB bacteriophage-encoded sponge RNA (Tree et al., 2014), which adds another layer of complexity: a sponge RNA can mitigate several sRNAs, and a single sRNA can be sequestered by more than one sponge RNA.

Besides 3' UTR mRNA-related biogenesis, sRNA sponges can also be generated from diverse loci such as tRNA transcripts, either mature or precursor tRNA (Lalaouna et al., 2015). During the maturation of the $g l y W$-cystT-leuZ polycistronic pre-tRNA, a 3' external transcribed spacer sequence (3' ETS ${ }^{\text {leuZ }}$ ) is released and acts as a sponge for RyhB and RybB sRNAs to reduce transcriptional noise during non-inducing conditions. RybB is also sponged by RbsZ, the sRNA associated with Hfq and ProQ (Melamed et al., 2020). Recent studies in the model organism E. coli demonstrated the presence of sRNA sponges ChiZ and IspZ deriving from 5' UTRs (Adams et al., 2021), suggesting that sponge RNAs can be produced from any part of the genome. They can thus be produced independently since they contain their own promoters, they can be processed from an existing transcript, they may belong to intergenic spacer regions or intergenic tRNA spacers, or they can be generated from 3' UTRs (Denham, 2020).

With the concept of sponge, it appears that the bioavailability of the mRNA target and the presence of a sponge RNA are important parts of sRNA-mediated gene regulation. The discovery of sRNA sponges is still recent, and more breakthroughs are expected in the near future, which should help us understand their importance in regulatory networks.

\section{Mediation of Transcription Termination}

In $E$. coli (and perhaps in all bacteria), sRNAs can affect gene expression through a variety of mechanisms of action. Another example of this extraordinary diversity is the ability of some sRNAs to mediate transcription termination. Study of the transcriptional regulation of the chiPQ operon by ChiX sRNAs revealed that by pairing with the $5^{\prime}$ end of its mRNA target, the sRNA induces Rho-dependent transcription termination (Bossi et al., 2012). The actual mechanism of action relies on the inhibition of ribosome binding, decreasing ribosomes at the Rho utilization site thus increasing Rho-dependent transcription termination. Conversely, other examples of positive regulation have been reported, with DsrA, ArcZ, and RprA regulating rpoS expression by preventing Rho from binding to the mRNA, while the sRNAs continue to bind the 5' UTRs (Sedlyarova et al., 2016). Transcription termination regulation by sRNAs was recently reviewed (Chen et al., 2019; Bossi et al., 2020).

\section{Clusters of Regularly Interspaced Short Palindromic Repeat}

Although, there has been an explosion of information about sRNA modes of action and expression, the general rule was that since RNA is the product of DNA transcription, it only rarely retroactively affects DNA. This dogma has been overturned with the discovery of clusters of regularly interspaced short palindromic repeats (CRISPRs), which provide immunity to bacteria by recognizing any re-invasion of nucleic acids (Barrangou et al., 2007). In CRISPR, a guide RNA (crRNA) is crucial for the recognition of foreign DNA or RNA (from bacteriophages, plasmids, or mobile genetic elements), enabling its cleavage by the Cas9 nuclease (Brouns et al., 2008). Following processing, the foreign sequence is integrated into the genome in a CRISPR array usually located close to the Cas system. The CRISPR array is composed of spacer sequences corresponding to foreign DNAs serving as immune memory, and which are flanked by DNA repeats. The DNA-encoded CRISPR system thus involves RNA-mediated recognition of foreign nucleic acids, and functions as a defense system.

\section{CONCLUDING REMARKS}

Over the past few decades, a tremendous shift has taken place in how we define RNA species. Although, they were long dismissed as simple messengers, the first in-depth characterizations of non-coding RNAs have paved the way for fascinating discoveries about their functions, which range from essential roles in translation machinery to global regulatory functions. Genomewide and high-throughput screenings have enabled a rapid evolution in knowledge, and the establishment of new rules. They helped reveal an extraordinary diversity in types of non-coding RNAs and showed that they use an abundance of mechanisms of action. Non-coding RNAs include rRNAs, tRNAs, 6S RNA, ribozymes, riboswitches, CRISPRs, and sRNAs. In terms 
of viability, sRNAs are often non-essential, but they are valuable for rapid and cost-effective regulation of gene expression in response to environmental cues. Therefore, they appear to be key players, adding another layer to gene expression control. Within sRNAs, a large number of classes and sub-classes have been created as a result of novel discoveries about their genomic locations, biogenesis, and modes of action, and these go way beyond protein classifications based solely on function and domain presence. In each sRNA category, there are a variety of mechanisms of action (with some appearing in several categories), and a large diversity of functions. The boundaries between sub-classes, between sRNAs and riboswitches or CRISPRs, sometimes appear very thin, particularly as novel mechanisms of action or biogenesis are constantly discovered. It is now accepted that their biogenesis can occur from any locus in the genome or in plasmids, and from any type of RNA molecule. Although categorization into multiple and highly specific types permits the organization of information, it may be detrimental for a rapid and simple presentation of what constitutes the sRNA. Cech and Steitz (2014) attempted to summarize the definition of sRNAs based on their most general function, basepairing with mRNAs to regulate gene expression. However, this definition is limited, as it does not include protein-binding sRNAs. Perhaps just minor adjustments are enough to ensure consensus around a definition expansive enough to avoid

\section{REFERENCES}

Acuña, L. G., Barros, M. J., Peñaloza, D., Rodas, P. I., Paredes-Sabja, D., Fuentes, J. A., et al. (2016). A feed-forward loop between SroC and MgrR small RNAs modulates the expression of eptB and the susceptibility to polymyxin B in Salmonella Typhimurium. Microbiology 162, 1996-2004. doi: $10.1099 / \mathrm{mic} .0 .000365$

Adams, P. P., Baniulyte, G., Esnault, C., Chegireddy, K., Singh, N., Monge, M., et al. (2021). Regulatory roles of Escherichia coli 5' UTR and ORF-internal RNAs detected by 3 ' end mapping. elife 10:e62438. doi: 10.7554/eLife.62438

Adams, P. P., Flores Avile, C., Popitsch, N., Bilusic, I., Schroeder, R., Lybecker, M., et al. (2017). In vivo expression technology and 5 ' end mapping of the Borrelia burgdorferi transcriptome identify novel RNAs expressed during mammalian infection. Nucleic Acids Res. 45, 775-792. doi: 10.1093/nar/ gkw1180

Alix, E., and Blanc-Potard, A.-B. (2008). Peptide-assisted degradation of the Salmonella MgtC virulence factor. EMBO J. 27, 546-557. doi: 10.1038/sj. emboj.7601983

Altman, S., Baer, M. F., Bartkiewicz, M., Gold, H., Guerrier-Takada, C., Kirsebom, L. A., et al. (1989). Catalysis by the RNA subunit of RNase P-a mini review. Gene 82, 63-64. doi: 10.1016/0378-1119(89)90030-9

Altuvia, S., Zhang, A., Argaman, L., Tiwari, A., and Storz, G. (1998). The Escherichia coli OxyS regulatory RNA represses fhlA translation by blocking ribosome binding. EMBO J. 17, 6069-6075. doi: 10.1093/emboj/17.20.6069

André, G., Even, S., Putzer, H., Burguière, P., Croux, C., Danchin, A., et al. (2008). S-box and T-box riboswitches and antisense RNA control a sulfur metabolic operon of Clostridium acetobutylicum. Nucleic Acids Res. 36, 5955-5969. doi: 10.1093/nar/gkn601

Arthur, D. C., Ghetu, A. F., Gubbins, M. J., Edwards, R. A., Frost, L. S., and Glover, J. N. M. (2003). FinO is an RNA chaperone that facilitates senseantisense RNA interactions. EMBO J. 22, 6346-6355. doi: 10.1093/emboj/ cdg607

Asano, K., and Mizobuchi, K. (1998a). An RNA pseudoknot as the molecular switch for translation of the repZ gene encoding the replication initiator of IncIalpha plasmid ColIb-P9. J. Biol. Chem. 273, 11815-11825. doi: 10.1074/ jbc.273.19.11815 obsolescence. Bacterial sRNAs are any RNA molecules that interact with other actors to regulate gene expression.

\section{AUTHOR CONTRIBUTIONS}

$\mathrm{BF}$ and YA planned the outline of the manuscript. YA wrote the review. All authors contributed to the article and approved the submitted version.

\section{FUNDING}

This work was funded by the University of Rennes 1 and the Institut National de la Santé et de la Recherche Médicale.

\section{ACKNOWLEDGMENTS}

This manuscript is dedicated to Brice Felden and to his passion for the RNA world and the multifaceted roles of bacterial sRNAs. The authors would like to thank Astrid Rouillon and Marie-Laure Pinel-Marie for reading the manuscript, and to Svetlana Chabelskaya for sharing the drawing of the structure of RNAIII.

Asano, K., and Mizobuchi, K. (1998b). Copy number control of IncIalpha plasmid ColIb-P9 by competition between pseudoknot formation and antisense RNA binding at a specific RNA site. EMBO J. 17, 5201-5213. doi: 10.1093/ emboj/17.17.5201

Attaiech, L., Boughammoura, A., Brochier-Armanet, C., Allatif, O., Peillard-Fiorente, F., Edwards, R. A., et al. (2016). Silencing of natural transformation by an RNA chaperone and a multitarget small RNA. Proc. Natl. Acad. Sci. U. S. A. 113, 8813-8818. doi: 10.1073/pnas.1601626113

Augagneur, Y., King, A. N., Germain-Amiot, N., Sassi, M., Fitzgerald, J. W., Sahukhal, G. S., et al. (2020). Analysis of the CodY RNome reveals RsaD as a stress-responsive riboregulator of overflow metabolism in Staphylococcus aureus. Mol. Microbiol. 113, 309-325. doi: 10.1111/mmi.14418

Augagneur, Y., Wesolowski, D., Tae, H. S., Altman, S., and Ben Mamoun, C. (2012). Gene selective mRNA cleavage inhibits the development of Plasmodium falciparum. Proc. Natl. Acad. Sci. U. S. A. 109, 6235-6240. doi: 10.1073/pnas.1203516109

Avila-Calderón, E. D., Araiza-Villanueva, M. G., Cancino-Diaz, J. C., López-Villegas, E. O., Sriranganathan, N., Boyle, S. M., et al. (2015). Roles of bacterial membrane vesicles. Arch. Microbiol. 197, 1-10. doi: 10.1007/ s00203-014-1042-7

Azam, M. S., and Vanderpool, C. K. (2015). Talk among yourselves: RNA sponges mediate cross talk between functionally related messenger RNAs. EMBO J. 34, 1436-1438. doi: 10.15252/embj.201591492

Babitzke, P., and Romeo, T. (2007). CsrB sRNA family: sequestration of RNAbinding regulatory proteins. Curr. Opin. Microbiol. 10, 156-163. doi: 10.1016/j. mib.2007.03.007

Balaban, N., and Novick, R. P. (1995). Translation of RNAIII, the Staphylococcus aureus agr regulatory RNA molecule, can be activated by a 3'-end deletion. FEMS Microbiol. Lett. 133, 155-161. doi: 10.1111/j.1574-6968.1995.tb07877.x

Balbontín, R., Fiorini, F., Figueroa-Bossi, N., Casadesús, J., and Bossi, L. (2010). Recognition of heptameric seed sequence underlies multi-target regulation by RybB small RNA in Salmonella enterica. Mol. Microbiol. 78, 380-394. doi: $10.1111 /$ j.1365-2958.2010.07342.x

Bandyra, K. J., Said, N., Pfeiffer, V., Górna, M. W., Vogel, J., and Luisi, B. F. (2012). The seed region of a small RNA drives the controlled destruction of the target mRNA by the endoribonuclease RNase E. Mol. Cell 47, 943953. doi: $10.1016 /$ j.molcel.2012.07.015 
Barrangou, R., Fremaux, C., Deveau, H., Richards, M., Boyaval, P., Moineau, S., et al. (2007). CRISPR provides acquired resistance against viruses in prokaryotes. Science 315, 1709-1712. doi: 10.1126/science.1138140

Bauriedl, S., Gerovac, M., Heidrich, N., Bischler, T., Barquist, L., Vogel, J., et al. (2020). The minimal meningococcal ProQ protein has an intrinsic capacity for structure-based global RNA recognition. Nat. Commun. 11:2823. doi: $10.1038 / s 41467-020-16650-6$

Beaume, M., Hernandez, D., Farinelli, L., Deluen, C., Linder, P., Gaspin, C., et al. (2010). Cartography of methicillin-resistant S. aureus transcripts: detection, orientation and temporal expression during growth phase and stress conditions. PLoS One 5:e10725. doi: 10.1371/journal.pone.0010725

Benito, Y., Kolb, F. A., Romby, P., Lina, G., Etienne, J., and Vandenesch, F. (2000). Probing the structure of RNAIII, the Staphylococcus aureus agr regulatory RNA, and identification of the RNA domain involved in repression of protein A expression. RNA 6, 668-679. doi: 10.1017/S1355838200 992550

Bessaiah, H., Pokharel, P., Loucif, H., Kulbay, M., Sasseville, C., Habouria, H., et al. (2021). The RyfA small RNA regulates oxidative and osmotic stress responses and virulence in uropathogenic Escherichia coli. PLoS Pathog. 17:e1009617. doi: 10.1371/journal.ppat.1009617

Bhatt, S., Egan, M., Jenkins, V., Muche, S., and El-Fenej, J. (2016). The tip of the iceberg: on the roles of regulatory small RNAs in the virulence of enterohemorrhagic and enteropathogenic Escherichia coli. Front. Cell. Infect. Microbiol. 6:105. doi: 10.3389/fcimb.2016.00105

Bohn, C., Rigoulay, C., and Bouloc, P. (2007). No detectable effect of RNAbinding protein Hfq absence in Staphylococcus aureus. BMC Microbiol. 7:10. doi: $10.1186 / 1471-2180-7-10$

Bohn, C., Rigoulay, C., Chabelskaya, S., Sharma, C. M., Marchais, A., Skorski, P., et al. (2010). Experimental discovery of small RNAs in Staphylococcus aureus reveals a riboregulator of central metabolism. Nucleic Acids Res. 38, 6620-6636. doi: $10.1093 /$ nar/gkq462

Boisset, S., Geissmann, T., Huntzinger, E., Fechter, P., Bendridi, N., Possedko, M., et al. (2007). Staphylococcus aureus RNAIII coordinately represses the synthesis of virulence factors and the transcription regulator rot by an antisense mechanism. Genes Dev. 21, 1353-1366. doi: 10.1101/gad.423507

Bossi, L., Figueroa-Bossi, N., Bouloc, P., and Boudvillain, M. (2020). Regulatory interplay between small RNAs and transcription termination factor rho. Biochim. Biophys Acta Gene Regul. Mech. 1863:194546. doi: 10.1016/j. bbagrm.2020.194546

Bossi, L., Schwartz, A., Guillemardet, B., Boudvillain, M., and Figueroa-Bossi, N. (2012). A role for rho-dependent polarity in gene regulation by a noncoding small RNA. Genes Dev. 26, 1864-1873. doi: 10.1101/gad.195412.112

Bouvier, M., Sharma, C. M., Mika, F., Nierhaus, K. H., and Vogel, J. (2008). Small RNA binding to 5' mRNA coding region inhibits translational initiation. Mol. Cell 32, 827-837. doi: 10.1016/j.molcel.2008.10.027

Brantl, S. (2002). Antisense-RNA regulation and RNA interference. Biochim. Biophys. Acta 1575, 15-25. doi: 10.1016/s0167-4781(02)00280-4

Brantl, S. (2007). Regulatory mechanisms employed by cis-encoded antisense RNAs. Curr. Opin. Microbiol. 10, 102-109. doi: 10.1016/j.mib.2007.03.012

Brantl, S., Birch-Hirschfeld, E., and Behnke, D. (1993). RepR protein expression on plasmid pIP501 is controlled by an antisense RNA-mediated transcription attenuation mechanism. J. Bacteriol. 175, 4052-4061. doi: 10.1128/ jb.175.13.4052-4061.1993

Brantl, S., and Jahn, N. (2015). sRNAs in bacterial type I and type III toxinantitoxin systems. FEMS Microbiol. Rev. 39, 413-427. doi: 10.1093/femsre/ fuv003

Brewer, S. M., Twittenhoff, C., Kortmann, J., Brubaker, S. W., Honeycutt, J., Massis, L. M., et al. (2021). A Salmonella Typhi RNA thermosensor regulates virulence factors and innate immune evasion in response to host temperature. PLoS Pathog. 17:e1009345. doi: 10.1371/journal.ppat.1009345

Bronesky, D., Desgranges, E., Corvaglia, A., François, P., Caballero, C. J., Prado, L., et al. (2019). A multifaceted small RNA modulates gene expression upon glucose limitation in Staphylococcus aureus. EMBO J. 38:e99363. doi: $10.15252 / \mathrm{embj} .201899363$

Bronesky, D., Wu, Z., Marzi, S., Walter, P., Geissmann, T., Moreau, K., et al. (2016). Staphylococcus aureus RNAIII and its regulon link quorum sensing, stress responses, metabolic adaptation, and regulation of virulence gene expression. Annu. Rev. Microbiol. 70, 299-316. doi: 10.1146/annurevmicro-102215-095708
Bronsard, J., Pascreau, G., Sassi, M., Mauro, T., Augagneur, Y., and Felden, B. (2017). sRNA and cis-antisense sRNA identification in Staphylococcus aureus highlights an unusual sRNA gene cluster with one encoding a secreted peptide. Sci. Rep. 7:4565. doi: 10.1038/s41598-017-04786-3

Brouns, S. J. J., Jore, M. M., Lundgren, M., Westra, E. R., Slijkhuis, R. J. H., Snijders, A. P. L., et al. (2008). Small CRISPR RNAs guide antiviral defense in prokaryotes. Science 321, 960-964. doi: 10.1126/science.1159689

Brownlee, G. G. (1971). Sequence of 6S RNA of E. coli. Nat. New Biol. 229, 147-149. doi: 10.1038/newbio229147a0

Burenina, O. Y., Oretskaya, T. S., and Kubareva, E. A. (2017). Non-coding RNAs as transcriptional regulators in eukaryotes. Acta Nat. 9, 13-25. doi: 10.32607/20758251-2017-9-4-13-25

Calderón, I. L., Morales, E. H., Collao, B., Calderón, P. F., Chahuán, C. A., Acuña, L. G., et al. (2014). Role of Salmonella Typhimurium small RNAs RyhB-1 and RyhB-2 in the oxidative stress response. Res. Microbiol. 165, 30-40. doi: 10.1016/j.resmic.2013.10.008

Carrier, M.-C., Lalaouna, D., and Massé, E. (2018). Broadening the definition of bacterial small RNAs: characteristics and mechanisms of action. Annu. Rev. Microbiol. 72, 141-161. doi: 10.1146/annurev-micro-090817-062607

Catalan-Moreno, A., Cela, M., Menendez-Gil, P., Irurzun, N., Caballero, C. J., Caldelari, I., et al. (2021). RNA thermoswitches modulate Staphylococcus aureus adaptation to ambient temperatures. Nucleic Acids Res. 49, 3409-3426. doi: $10.1093 /$ nar/gkab117

Cech, T. R., and Steitz, J. A. (2014). The noncoding RNA revolution-trashing old rules to forge new ones. Cell 157, 77-94. doi: 10.1016/j.cell.2014.03.008

Chabelskaya, S., Bordeau, V., and Felden, B. (2014). Dual RNA regulatory control of a Staphylococcus aureus virulence factor. Nucleic Acids Res. 42, 4847-4858. doi: 10.1093/nar/gku119

Chabelskaya, S., Gaillot, O., and Felden, B. (2010). A Staphylococcus aureus small RNA is required for bacterial virulence and regulates the expression of an immune-evasion molecule. PLoS Pathog. 6:e1000927. doi: 10.1371/ journal.ppat.1000927

Chao, Y., Papenfort, K., Reinhardt, R., Sharma, C. M., and Vogel, J. (2012). An atlas of Hfq-bound transcripts reveals 3' UTRs as a genomic reservoir of regulatory small RNAs. EMBO J. 31, 4005-4019. doi: 10.1038/emboj.2012.229

Chao, Y., and Vogel, J. (2016). A 3' UTR-derived small RNA provides the regulatory noncoding arm of the inner membrane stress response. Mol. Cell 61, 352-363. doi: 10.1016/j.molcel.2015.12.023

Chareyre, S., Barras, F., and Mandin, P. (2019). A small RNA controls bacterial sensitivity to gentamicin during iron starvation. PLoS Genet. 15:e1008078. doi: 10.1371/journal.pgen.1008078

Chareyre, S., and Mandin, P. (2018). Bacterial iron homeostasis regulation by sRNAs. Microbiol. Spectr. 6. doi: 10.1128/microbiolspec.RWR-0010-2017

Chen, L., Huang, C., Wang, X., and Shan, G. (2015). Circular RNAs in eukaryotic cells. Curr. Genomics 16, 312-318. doi: 10.2174/138920291666615070716155 4

Chen, J., Morita, T., and Gottesman, S. (2019). Regulation of transcription termination of small RNAs and by small RNAs: molecular mechanisms and biological functions. Front. Cell. Infect. Microbiol. 9:201. doi: 10.3389/ fcimb. 2019.00201

Chevalier, C., Boisset, S., Romilly, C., Masquida, B., Fechter, P., Geissmann, T., et al. (2010). Staphylococcus aureus RNAIII binds to two distant regions of coa mRNA to arrest translation and promote mRNA degradation. PLoS Pathog. 6:e1000809. doi: 10.1371/journal.ppat.1000809

Christiansen, J. K., Larsen, M. H., Ingmer, H., Søgaard-Andersen, L., and Kallipolitis, B. H. (2004). The RNA-binding protein Hfq of Listeria monocytogenes: role in stress tolerance and virulence. J. Bacteriol. 186, 3355-3362. doi: 10.1128/JB.186.11.3355-3362.2004

Christiansen, J. K., Nielsen, J. S., Ebersbach, T., Valentin-Hansen, P., Søgaard-Andersen, L., and Kallipolitis, B. H. (2006). Identification of small Hfq-binding RNAs in Listeria monocytogenes. RNA 12, 1383-1396. doi: 10.1261/rna.49706

Chunhua, M., Yu, L., Yaping, G., Jie, D., Qiang, L., Xiaorong, T., et al. (2012). The expression of LytM is down-regulated by RNAIII in Staphylococcus aureus. J. Basic Microbiol. 52, 636-641. doi: 10.1002/jobm.201100426

Correia Santos, S., Bischler, T., Westermann, A. J., and Vogel, J. (2021). MAPS integrates regulation of actin-targeting effector SteC into the virulence control network of Salmonella small RNA PinT. Cell Rep. 34:108722. doi: 10.1016/j. celrep.2021.108722 
Cotter, R. I., McPhie, P., and Gratzer, W. B. (1967). Internal organization of the ribosome. Nature 216, 864-868. doi: 10.1038/216864a0

Crick, F. H. (1958). On protein synthesis. Symp. Soc. Exp. Biol. 12, 138-163.

Crick, F. (1970). Central dogma of molecular biology. Nature 227, 561-563. doi: $10.1038 / 227561 \mathrm{a} 0$

Cue, D., Lei, M. G., and Lee, C. Y. (2012). Genetic regulation of the intercellular adhesion locus in staphylococci. Front. Cell. Infect. Microbiol. 2:38. doi: 10.3389/fcimb. 2012.00038

Dar, D., Shamir, M., Mellin, J. R., Koutero, M., Stern-Ginossar, N., Cossart, P., et al. (2016). Term-seq reveals abundant ribo-regulation of antibiotics resistance in bacteria. Science 352:aad9822. doi: 10.1126/science.aad 9822

Dar, D., and Sorek, R. (2018). Bacterial noncoding RNAs excised from within protein-coding transcripts. MBio 9, e01730-e01818. doi: 10.1128/mBio.01730-18

Das, S., Lindemann, C., Young, B. C., Muller, J., Osterreich, B., Ternette, N., et al. (2016). Natural mutations in a Staphylococcus aureus virulence regulator attenuate cytotoxicity but permit bacteremia and abscess formation. Proc. Natl. Acad. Sci. U. S. A. 113, E3101-E3110. doi: 10.1073/pnas.1520255113

Deana, A., and Belasco, J. G. (2005). Lost in translation: the influence of ribosomes on bacterial mRNA decay. Genes Dev. 19, 2526-2533. doi: 10.1101/ gad. 1348805

DebRoy, S., Gebbie, M., Ramesh, A., Goodson, J. R., Cruz, M. R., van Hoof, A., et al. (2014). Riboswitches. A riboswitch-containing sRNA controls gene expression by sequestration of a response regulator. Science 345, 937-940. doi: $10.1126 /$ science.1255091

Denham, E. L. (2020). The sponge RNAs of bacteria-how to find them and their role in regulating the post-transcriptional network. Biochim. Biophys Acta Gene Regul. Mech. 1863:194565. doi: 10.1016/j.bbagrm.2020.194565

Derksen, M., Mertens, V., and Pruijn, G. J. M. (2015). RNase P-mediated sequence-specific cleavage of RNA by engineered external guide sequences. Biomol. Ther. 5, 3029-3050. doi: 10.3390/biom5043029

Dühring, U., Axmann, I. M., Hess, W. R., and Wilde, A. (2006). An internal antisense RNA regulates expression of the photosynthesis gene isiA. Proc. Natl. Acad. Sci. U. S. A. 103, 7054-7058. doi: 10.1073/pnas.0600927103

Dunman, P. M., Murphy, E., Haney, S., Palacios, D., Tucker-Kellogg, G., Wu, S., et al. (2001). Transcription profiling-based identification of Staphylococcus aureus genes regulated by the agr and/or sarA loci. J. Bacteriol. 183, 7341-7353. doi: 10.1128/JB.183.24.7341-7353.2001

Dutta, T., and Srivastava, S. (2018). Small RNA-mediated regulation in bacteria: a growing palette of diverse mechanisms. Gene 656, 60-72. doi: 10.1016/j. gene.2018.02.068

Ellis, T. N., and Kuehn, M. J. (2010). Virulence and immunomodulatory roles of bacterial outer membrane vesicles. Microbiol. Mol. Biol. Rev. 74, 81-94. doi: 10.1128/MMBR.00031-09

Eyraud, A., Tattevin, P., Chabelskaya, S., and Felden, B. (2014). A small RNA controls a protein regulator involved in antibiotic resistance in Staphylococcus aureus. Nucleic Acids Res. 42, 4892-4905. doi: 10.1093/nar/gku149

Felden, B., and Cattoir, V. (2018). Bacterial adaptation to antibiotics through regulatory RNAs. Antimicrob. Agents Chemother. 62, e02503-e02517. doi: 10.1128/AAC.02503-17

Feng, L., Rutherford, S. T., Papenfort, K., Bagert, J. D., van Kessel, J. C., Tirrell, D. A., et al. (2015). A qrr noncoding RNA deploys four different regulatory mechanisms to optimize quorum-sensing dynamics. Cell 160, 228-240. doi: 10.1016/j.cell.2014.11.051

Ferrara, S., Falcone, M., Macchi, R., Bragonzi, A., Girelli, D., Cariani, L., et al. (2017). The PAPI-1 pathogenicity island-encoded small RNA PesA influences Pseudomonas aeruginosa virulence and modulates pyocin S3 production. PLoS One 12:e180386. doi: 10.1371/journal.pone.0180386

Figueroa-Bossi, N., Valentini, M., Malleret, L., Fiorini, F., and Bossi, L. (2009). Caught at its own game: regulatory small RNA inactivated by an inducible transcript mimicking its target. Genes Dev. 23, 2004-2015. doi: 10.1101/ gad.541609

Foster, T. J. (2005). Immune evasion by staphylococci. Nat. Rev. Microbiol. 3, 948-958. doi: 10.1038/nrmicro1289

Fröhlich, K. S., Papenfort, K., Berger, A. A., and Vogel, J. (2012). A conserved RpoS-dependent small RNA controls the synthesis of major porin OmpD. Nucleic Acids Res. 40, 3623-3640. doi: 10.1093/nar/gkr1156

Fröhlich, K. S., Papenfort, K., Fekete, A., and Vogel, J. (2013). A small RNA activates CFA synthase by isoform-specific mRNA stabilization. EMBO J. 32, 2963-2979. doi: 10.1038/emboj.2013.222
Gao, W., Guérillot, R., Lin, Y. H., Tree, J., Beaume, M., François, P., et al. (2020). Comparative transcriptomic and functional assessments of linezolidresponsive small RNA genes in Staphylococcus aureus. mSystems 5, e00665-e00719. doi: 10.1128/mSystems.00665-19

Geisinger, E., Adhikari, R. P., Jin, R., Ross, H. F., and Novick, R. P. (2006). Inhibition of rot translation by RNAIII, a key feature of agr function. Mol. Microbiol. 61, 1038-1048. doi: 10.1111/j.1365-2958.2006.05292.x

Geissmann, T., Chevalier, C., Cros, M. J., Boisset, S., Fechter, P., Noirot, C., et al. (2009). A search for small noncoding RNAs in Staphylococcus aureus reveals a conserved sequence motif for regulation. Nucleic Acids Res. 37, 7239-7257. doi: 10.1093/nar/gkp668

Germain-Amiot, N., Augagneur, Y., Camberlein, E., Nicolas, I., Lecureur, V., Rouillon, A., et al. (2019). A novel Staphylococcus aureus cis-trans type I toxin-antitoxin module with dual effects on bacteria and host cells. Nucleic Acids Res. 47, 1759-1773. doi: 10.1093/nar/gky1257

Giangrossi, M., Prosseda, G., Tran, C. N., Brandi, A., Colonna, B., and Falconi, M. (2010). A novel antisense RNA regulates at transcriptional level the virulence gene icsA of Shigella flexneri. Nucleic Acids Res. 38, 3362-3375. doi: 10.1093/ nar/gkq025

Gilbert, W. (1986). Origin of life: the RNA world. Nature 319:618. doi: $10.1038 / 319618 \mathrm{a} 0$

Gimpel, M., and Brantl, S. (2017). Dual-function small regulatory RNAs in bacteria. Mol. Microbiol. 103, 387-397. doi: 10.1111/mmi.13558

Gong, H., Vu, G.-P., Bai, Y., Chan, E., Wu, R., Yang, E., et al. (2011). A Salmonella small non-coding RNA facilitates bacterial invasion and intracellular replication by modulating the expression of virulence factors. PLoS Pathog. 7:e1002120. doi: 10.1371/journal.ppat.1002120

Göpel, Y., Khan, M. A., and Görke, B. (2014). Ménage à trois: post-transcriptional control of the key enzyme for cell envelope synthesis by a base-pairing small RNA, an RNase adaptor protein, and a small RNA mimic. RNA Biol. 11, 433-442. doi: 10.4161/rna.28301

Gorski, S. A., Vogel, J., and Doudna, J. A. (2017). RNA-based recognition and targeting: sowing the seeds of specificity. Nat. Rev. Mol. Cell Biol. 18, 215-228. doi: $10.1038 / \mathrm{nrm} .2016 .174$

Gripenland, J., Netterling, S., Loh, E., Tiensuu, T., Toledo-Arana, A., and Johansson, J. (2010). RNAs: regulators of bacterial virulence. Nat. Rev. Microbiol. 8, 857-866. doi: 10.1038/nrmicro2457

Gruber, C. C., and Sperandio, V. (2014). Posttranscriptional control of microbeinduced rearrangement of host cell actin. MBio 5, e01025-e01113. doi: 10.1128/mBio.01025-13

Gruber, C. C., and Sperandio, V. (2015). Global analysis of posttranscriptional regulation by GlmY and GlmZ in enterohemorrhagic Escherichia coli O157:H7. Infect. Immun. 83, 1286-1295. doi: 10.1128/IAI.02918-14

Guerrier-Takada, C., Gardiner, K., Marsh, T., Pace, N., and Altman, S. (1983). The RNA moiety of ribonuclease $\mathrm{P}$ is the catalytic subunit of the enzyme. Cell 35, 849-857. doi: 10.1016/0092-8674(83)90117-4

Gupta, R. K., Luong, T. T., and Lee, C. Y. (2015). RNAIII of the Staphylococcus aureus agr system activates global regulator MgrA by stabilizing mRNA. Proc. Natl. Acad. Sci. U. S. A. 112, 14036-14041. doi: 10.1073/pnas.1509 251112

Hausmann, S., Guimarães, V. A., Garcin, D., Baumann, N., Linder, P., and Redder, P. (2017). Both exo- and endo-nucleolytic activities of RNase J1 from Staphylococcus aureus are manganese dependent and active on triphosphorylated 5'-ends. RNA Biol. 14, 1431-1443. doi: 10.1080/15476286.2017.1300223

Heidrich, N., Bauriedl, S., Barquist, L., Li, L., Schoen, C., and Vogel, J. (2017). The primary transcriptome of Neisseria meningitidis and its interaction with the RNA chaperone Hfq. Nucleic Acids Res. 45, 6147-6167. doi: 10.1093/ nar/gkx168

Hindley, J. (1967). Fractionation of 32P-labelled ribonucleic acids on polyacrylamide gels and their characterization by fingerprinting. J. Mol. Biol. 30, 125-136. doi: 10.1016/0022-2836(67)90248-3

Hoagland, M. B., Stephenson, M. L., Scott, J. F., Hecht, L. I., and Zamecnik, P. C. (1958). A soluble ribonucleic acid intermediate in protein synthesis. J. Biol. Chem. 231, 241-257. doi: 10.1016/S0021-9258(19)77302-5

Howden, B. P., Beaume, M., Harrison, P. F., Hernandez, D., Schrenzel, J., Seemann, T., et al. (2013). Analysis of the small RNA transcriptional response in multidrug-resistant Staphylococcus aureus after antimicrobial exposure. Antimicrob. Agents Chemother. 57, 3864-3874. doi: 10.1128/AAC.00263-13 
Hoyos, M., Huber, M., Förstner, K. U., and Papenfort, K. (2020). Gene autoregulation by 3' UTR-derived bacterial small RNAs. elife 9:e58836. doi: 10.7554/eLife.58836

Huntzinger, E., Boisset, S., Saveanu, C., Benito, Y., Geissmann, T., Namane, A., et al. (2005). Staphylococcus aureus RNAIII and the endoribonuclease III coordinately regulate spa gene expression. EMBO J. 24, 824-835. doi: 10.1038/ sj.emboj.7600572

Hussein, H., Fris, M. E., Salem, A. H., Wiemels, R. E., Bastock, R. A., Righetti, F., et al. (2019). An unconventional RNA-based thermosensor within the 5' UTR of Staphylococcus aureus cidA. PLoS One 14:e0214521. doi: 10.1371/ journal.pone.0214521

Hüttenhofer, A., and Noller, H. F. (1994). Footprinting mRNA-ribosome complexes with chemical probes. EMBO J. 13, 3892-3901. doi: 10.1002/j.1460-2075.1994. tb06700.x

Ikeda, Y., Yagi, M., Morita, T., and Aiba, H. (2011). Hfq binding at RhlBrecognition region of RNase $\mathrm{E}$ is crucial for the rapid degradation of target mRNAs mediated by sRNAs in Escherichia coli. Mol. Microbiol. 79, 419-432. doi: 10.1111/j.1365-2958.2010.07454.x

Ikemura, T., and Dahlberg, J. E. (1973). Small ribonucleic acids of Escherichia coli. I. Characterization by polyacrylamide gel electrophoresis and fingerprint analysis. J. Biol. Chem. 248, 5024-5032. doi: 10.1016/S0021-9258(19)43666-1

Ingavale, S., van Wamel, W., Luong, T. T., Lee, C. Y., and Cheung, A. L. (2005). Rat/MgrA, a regulator of autolysis, is a regulator of virulence genes in Staphylococcus aureus. Infect. Immun. 73, 1423-1431. doi: 10.1128/ IAI.73.3.1423-1431.2005

Janssen, K. H., Diaz, M. R., Gode, C. J., Wolfgang, M. C., and Yahr, T. L. (2018). RsmV, a small noncoding regulatory RNA in Pseudomonas aeruginosa that sequesters RsmA and RsmF from target mRNAs. J. Bacteriol. 200, e00277-e00318. doi: 10.1128/JB.00277-18

Janssen, B. D., and Hayes, C. S. (2012). The tmRNA ribosome-rescue system. Adv. Protein Chem. Struct. Biol. 86, 151-191. doi: 10.1016/ B978-0-12-386497-0.00005-0

Jia, T., Liu, B., Mu, H., Qian, C., Wang, L., Li, L., et al. (2021). A novel small RNA promotes motility and virulence of enterohemorrhagic Escherichia coli O157:H7 in response to ammonium. MBio 12, e03605-e03620. doi: 10.1128/ mBio.03605-20

Johansson, J., Mandin, P., Renzoni, A., Chiaruttini, C., Springer, M., and Cossart, P. (2002). An RNA thermosensor controls expression of virulence genes in Listeria monocytogenes. Cell 110, 551-561. doi: 10.1016/ s0092-8674(02)00905-4

Jørgensen, M. G., Pettersen, J. S., and Kallipolitis, B. H. (2020). sRNA-mediated control in bacteria: an increasing diversity of regulatory mechanisms. Biochim. Biophys Acta Gene Regul. Mech. 1863:194504. doi: 10.1016/j.bbagrm.2020.194504

Joshi, B., Singh, B., Nadeem, A., Askarian, F., Wai, S. N., Johannessen, M., et al. (2020). Transcriptome profiling of Staphylococcus aureus associated extracellular vesicles reveals presence of small RNA-cargo. Front. Mol. Biosci. 7:566207. doi: $10.3389 /$ fmolb.2020.566207

Kavita, K., de Mets, F., and Gottesman, S. (2018). New aspects of RNA-based regulation by Hfq and its partner sRNAs. Curr. Opin. Microbiol. 42, 53-61. doi: 10.1016/j.mib.2017.10.014

Kim, J. N. (2016). Roles of two RyhB paralogs in the physiology of Salmonella enterica. Microbiol. Res. 186-187, 146-152. doi: 10.1016/j.micres.2016.04.004

Kim, J. N., and Kwon, Y. M. (2013). Identification of target transcripts regulated by small RNA RyhB homologs in Salmonella: RyhB-2 regulates motility phenotype. Microbiol. Res. 168, 621-629. doi: 10.1016/j.micres.2013.06.002

Kim, S., Reyes, D., Beaume, M., Francois, P., and Cheung, A. (2014). Contribution of teg49 small RNA in the $5^{\prime}$ upstream transcriptional region of sarA to virulence in Staphylococcus aureus. Infect. Immun. 82, 4369-4379. doi: 10.1128/IAI.02002-14

Kinoshita-Daitoku, R., Kiga, K., Miyakoshi, M., Otsubo, R., Ogura, Y., Sanada, T., et al. (2021). A bacterial small RNA regulates the adaptation of helicobacter pylori to the host environment. Nat. Commun. 12:2085. doi: 10.1038/ s41467-021-22317-7

Koeppen, K., Hampton, T. H., Jarek, M., Scharfe, M., Gerber, S. A., Mielcarz, D. W., et al. (2016). A novel mechanism of host-pathogen interaction through sRNA in bacterial outer membrane vesicles. PLoS Pathog. 12:e1005672. doi: 10.1371/journal.ppat.1005672

Kole, R., Krainer, A. R., and Altman, S. (2012). RNA therapeutics: beyond RNA interference and antisense oligonucleotides. Nat. Rev. Drug Discov. 11, 125-140. doi: $10.1038 / \operatorname{nrd} 3625$
Kortmann, J., and Narberhaus, F. (2012). Bacterial RNA thermometers: molecular zippers and switches. Nat. Rev. Microbiol. 10, 255-265. doi: 10.1038/nrmicro2730

Lalaouna, D., Baude, J., Wu, Z., Tomasini, A., Chicher, J., Marzi, S., et al. (2019). RsaC sRNA modulates the oxidative stress response of Staphylococcus aureus during manganese starvation. Nucleic Acids Res. 47, 9871-9887. doi: 10.1093/nar/gkz728

Lalaouna, D., Carrier, M.-C., Semsey, S., Brouard, J.-S., Wang, J., Wade, J. T., et al. (2015). A 3' external transcribed spacer in a tRNA transcript acts as a sponge for small RNAs to prevent transcriptional noise. Mol. Cell 58, 393-405. doi: 10.1016/j.molcel.2015.03.013

Lalaouna, D., Prevost, K., Eyraud, A., and Masse, E. (2017). Identification of unknown RNA partners using MAPS. Methods 117, 28-34. doi: 10.1016/j. ymeth.2016.11.011

Lasa, I., Toledo-Arana, A., Dobin, A., Villanueva, M., de los Mozos, I. R., Vergara-Irigaray, M., et al. (2011). Genome-wide antisense transcription drives mRNA processing in bacteria. Proc. Natl. Acad. Sci. U. S. A. 108, 20172-20177. doi: 10.1073/pnas.1113521108

Leclerc, J.-M., Dozois, C. M., and Daigle, F. (2013). Role of the Salmonella enterica serovar Typhi Fur regulator and small RNAs RfrA and RfrB in iron homeostasis and interaction with host cells. Microbiology 159, 591-602. doi: $10.1099 /$ mic.0.064329-0

Lee, E.-J., and Groisman, E. A. (2010). An antisense RNA that governs the expression kinetics of a multifunctional virulence gene. Mol. Microbiol. 76, 1020-1033. doi: 10.1111/j.1365-2958.2010.07161.x

Lee, J. Y. H., Monk, I. R., Gonçalves da Silva, A., Seemann, T., Chua, K. Y. L., Kearns, A., et al. (2018). Global spread of three multidrug-resistant lineages of Staphylococcus epidermidis. Nat. Microbiol. 3, 1175-1185. doi: 10.1038/ s41564-018-0230-7

Lejars, M., and Hajnsdorf, E. (2020). The world of asRNAs in gram-negative and gram-positive bacteria. Biochim. Biophys Acta Gene Regul. Mech. 1863:194489. doi: 10.1016/j.bbagrm.2020.194489

Lemon, K. P., Higgins, D. E., and Kolter, R. (2007). Flagellar motility is critical for Listeria monocytogenes biofilm formation. J. Bacteriol. 189, 4418-4424. doi: 10.1128/JB.01967-06

Le Pabic, H., Germain-Amiot, N., Bordeau, V., and Felden, B. (2015). A bacterial regulatory RNA attenuates virulence, spread and human host cell phagocytosis. Nucleic Acids Res. 43, 9232-9248. doi: 10.1093/nar/gkv783

Le Scornet, A., and Redder, P. (2019). Post-transcriptional control of virulence gene expression in Staphylococcus aureus. Biochim. Biophys Acta Gene Regul. Mech. 1862, 734-741. doi: 10.1016/j.bbagrm.2018.04.004

Lioliou, E., Romilly, C., Romby, P., and Fechter, P. (2010). RNA-mediated regulation in bacteria: from natural to artificial systems. New Biotechnol. 27, 222-235. doi: 10.1016/j.nbt.2010.03.002

Liu, M. Y., Gui, G., Wei, B., Preston, J. F., Oakford, L., Yüksel, U., et al. (1997). The RNA molecule CsrB binds to the global regulatory protein CsrA and antagonizes its activity in Escherichia coli. J. Biol. Chem. 272, 17502-17510. doi: $10.1074 /$ jbc.272.28.17502

Liu, Y., Mu, C., Ying, X., Li, W., Wu, N., Dong, J., et al. (2011). RNAIII activates map expression by forming an RNA-RNA complex in Staphylococcus aureus. FEBS Lett. 585, 899-905. doi: 10.1016/j.febslet.2011.02.021

Loh, E., Dussurget, O., Gripenland, J., Vaitkevicius, K., Tiensuu, T., Mandin, P., et al. (2009). A trans-acting riboswitch controls expression of the virulence regulator PrfA in Listeria monocytogenes. Cell 139, 770-779. doi: 10.1016/j. cell.2009.08.046

Loh, E., Righetti, F., Eichner, H., Twittenhoff, C., and Narberhaus, F. (2018). RNA thermometers in bacterial pathogens. Microbiol. Spectr. 6. doi: 10.1128/ microbiolspec.RWR-0012-2017

Luirink, J., and Dobberstein, B. (1994). Mammalian and Escherichia coli signal recognition particles. Mol. Microbiol. 11, 9-13. doi: 10.1111/j.1365-2958.1994. tb00284.x

Luong, T. T., Dunman, P. M., Murphy, E., Projan, S. J., and Lee, C. Y. (2006). Transcription profiling of the mgrA regulon in Staphylococcus aureus. J. Bacteriol. 188, 1899-1910. doi: 10.1128/JB.188.5.1899-1910.2006

Luz, B. S. R. D., Nicolas, A., Chabelskaya, S., Rodovalho, V., de Rezende Rodovalho, V., Le Loir, Y., et al. (2021). Environmental plasticity of the RNA content of Staphylococcus aureus extracellular vesicles. Front. Microbiol. 12:634226. doi: $10.3389 /$ fmicb.2021.634226

Mader, U., Nicolas, P., Depke, M., Pane-Farre, J., Debarbouille, M., van der Kooi-Pol, M. M., et al. (2016). Staphylococcus aureus transcriptome 
architecture: from laboratory to infection-mimicking conditions. PLoS Genet. 12:e1005962. doi: 10.1371/journal.pgen.1005962

Mandin, P., Repoila, F., Vergassola, M., Geissmann, T., and Cossart, P. (2007). Identification of new noncoding RNAs in Listeria monocytogenes and prediction of mRNA targets. Nucleic Acids Res. 35, 962-974. doi: 10.1093/nar/gkl1096

Manna, A. C., Kim, S., Cengher, L., Corvaglia, A., Leo, S., Francois, P., et al. (2018). Small RNA teg49 is derived from a sarA transcript and regulates virulence genes independent of SarA in Staphylococcus aureus. Infect. Immun. 86, e00635-e00717. doi: 10.1128/IAI.00635-17

Massé, E., Escorcia, F. E., and Gottesman, S. (2003). Coupled degradation of a small regulatory RNA and its mRNA targets in Escherichia coli. Genes Dev. 17, 2374-2383. doi: 10.1101/gad.1127103

Massé, E., and Gottesman, S. (2002). A small RNA regulates the expression of genes involved in iron metabolism in Escherichia coli. Proc. Natl. Acad. Sci. U. S. A. 99, 4620-4625. doi: 10.1073/pnas.032066599

McDaniel, B. A. M., Grundy, F. J., Artsimovitch, I., and Henkin, T. M. (2003). Transcription termination control of the S box system: direct measurement of S-adenosylmethionine by the leader RNA. Proc. Natl. Acad. Sci. U. S. A. 100, 3083-3088. doi: 10.1073/pnas.0630422100

Mediati, D. G., Wu, S., Wu, W., and Tree, J. J. (2021). Networks of resistance: small RNA control of antibiotic resistance. Trends Genet. 37, 35-45. doi: 10.1016/j.tig.2020.08.016

Melamed, S., Adams, P. P., Zhang, A., Zhang, H., and Storz, G. (2020). RNARNA interactomes of ProQ and Hfq reveal overlapping and competing roles. Mol. Cell 77, 411.e7-425.e7. doi: 10.1016/j.molcel.2019.10.022

Melamed, S., Peer, A., Faigenbaum-Romm, R., Gatt, Y. E., Reiss, N., Bar, A., et al. (2016). Global mapping of small RNA-target interactions in bacteria. Mol. Cell 63, 884-897. doi: 10.1016/j.molcel.2016.07.026

Mellin, J. R., and Cossart, P. (2012). The non-coding RNA world of the bacterial pathogen Listeria monocytogenes. RNA Biol. 9, 372-378. doi: 10.4161/rna.19235

Mellin, J. R., and Cossart, P. (2015). Unexpected versatility in bacterial riboswitches. Trends Genet. 31, 150-156. doi: 10.1016/j.tig.2015.01.005

Mellin, J. R., Koutero, M., Dar, D., Nahori, M.-A., Sorek, R., and Cossart, P. (2014). Riboswitches. Sequestration of a two-component response regulator by a riboswitch-regulated noncoding RNA. Science 345, 940-943. doi: 10.1126/ science. 1255083

Mellin, J. R., Tiensuu, T., Bécavin, C., Gouin, E., Johansson, J., and Cossart, P. (2013). A riboswitch-regulated antisense RNA in Listeria monocytogenes. Proc. Natl. Acad. Sci. U. S. A. 110, 13132-13137. doi: 10.1073/pnas.1304 795110

Melson, E. M., and Kendall, M. M. (2019). The sRNA DicF integrates oxygen sensing to enhance enterohemorrhagic Escherichia coli virulence via distinctive RNA control mechanisms. Proc. Natl. Acad. Sci. U. S. A. 116, 14210-14215. doi: $10.1073 /$ pnas. 1902725116

Menendez-Gil, P., and Toledo-Arana, A. (2020). Bacterial 3'UTRs: a useful resource in post-transcriptional regulation. Front. Mol. Biosci. 7:617633. doi: 10.3389/fmolb.2020.617633

Mironov, A. S., Gusarov, I., Rafikov, R., Lopez, L. E., Shatalin, K., Kreneva, R. A., et al. (2002). Sensing small molecules by nascent RNA: a mechanism to control transcription in bacteria. Cell 111, 747-756. doi: 10.1016/ S0092-8674(02)01134-0

Miyakoshi, M., Chao, Y., and Vogel, J. (2015a). Cross talk between ABC transporter mRNAs via a target mRNA-derived sponge of the GcvB small RNA. EMBO J. 34, 1478-1492. doi: 10.15252/embj.201490546

Miyakoshi, M., Chao, Y., and Vogel, J. (2015b). Regulatory small RNAs from the 3' regions of bacterial mRNAs. Curr. Opin. Microbiol. 24, 132-139. doi: 10.1016/j.mib.2015.01.013

Miyakoshi, M., Matera, G., Maki, K., Sone, Y., and Vogel, J. (2019). Functional expansion of a TCA cycle operon mRNA by a 3 ' end-derived small RNA. Nucleic Acids Res. 47, 2075-2088. doi: 10.1093/nar/gky1243

Mizuno, T., Chou, M. Y., and Inouye, M. (1984). A unique mechanism regulating gene expression: translational inhibition by a complementary RNA transcript (micRNA). Proc. Natl. Acad. Sci. U. S. A. 81, 1966-1970.

Morfeldt, E., Taylor, D., von Gabain, A., and Arvidson, S. (1995). Activation of alpha-toxin translation in Staphylococcus aureus by the trans-encoded antisense RNA, RNAIII. EMBO J. 14, 4569-4577. doi: 10.1002/j.1460-2075.1995. tb00136.x

Moriano-Gutierrez, S., Bongrand, C., Essock-Burns, T., Wu, L., McFall-Ngai, M. J., and Ruby, E. G. (2020). The noncoding small RNA SsrA is released by
Vibrio fischeri and modulates critical host responses. PLoS Biol. 18:e3000934. doi: 10.1371/journal.pbio.3000934

Morita, T., Maki, K., and Aiba, H. (2005). RNase E-based ribonucleoprotein complexes: mechanical basis of mRNA destabilization mediated by bacteria noncoding RNAs. Genes Dev. 19, 2176-2186. doi: 10.1101/gad.1330405

Morrison, J. M., Miller, E. W., Benson, M. A., Alonzo, F. 3rd., Yoong, P., Torres, V. J., et al. (2012). Characterization of SSR42, a novel virulence factor regulatory RNA that contributes to the pathogenesis of a Staphylococcus aureus USA300 representative. J. Bacteriol. 194, 2924-2938. doi: 10.1128/ JB.06708-11

Mraheil, M. A., Billion, A., Mohamed, W., Mukherjee, K., Kuenne, C., Pischimarov, J., et al. (2011). The intracellular sRNA transcriptome of Listeria monocytogenes during growth in macrophages. Nucleic Acids Res. 39, 4235-4248. doi: 10.1093/nar/gkr033

Müller, P., Gimpel, M., Wildenhain, T., and Brantl, S. (2019). A new role for CsrA: promotion of complex formation between an sRNA and its mRNA target in Bacillus subtilis. RNA Biol. 16, 972-987. doi: 10.1080/15476286.2019.1605811

Ng Kwan Lim, E., Sasseville, C., Carrier, M.-C., and Massé, E. (2021). Keeping up with RNA-based regulation in bacteria: new roles for RNA binding proteins. Trends Genet. 37, 86-97. doi: 10.1016/j.tig.2020.09.014

Nielsen, J. S., Larsen, M. H., Lillebæk, E. M. S., Bergholz, T. M., Christiansen, M. H. G., Boor, K. J., et al. (2011). A small RNA controls expression of the chitinase ChiA in Listeria monocytogenes. PLoS One 6:e19019. doi: 10.1371/journal.pone.0019019

Nielsen, J. S., Lei, L. K., Ebersbach, T., Olsen, A. S., Klitgaard, J. K., Valentin-Hansen, P., et al. (2010). Defining a role for Hfq in gram-positive bacteria: evidence for $\mathrm{Hfq}$-dependent antisense regulation in Listeria monocytogenes. Nucleic Acids Res. 38, 907-919. doi: 10.1093/nar/ gkp1081

Nitzan, M., Fechter, P., Peer, A., Altuvia, Y., Bronesky, D., Vandenesch, F., et al. (2015). A defense-offense multi-layered regulatory switch in a pathogenic bacterium. Nucleic Acids Res. 43, 1357-1369. doi: 10.1093/nar/gkv001

Novick, R. P., Iordanescu, S., Projan, S. J., Kornblum, J., and Edelman, I. (1989). pT181 plasmid replication is regulated by a countertranscript-driven transcriptional attenuator. Cell 59, 395-404. doi: 10.1016/0092-8674(89)90300-0

Novick, R. P., Ross, H. F., Projan, S. J., Kornblum, J., Kreiswirth, B., and Moghazeh, S. (1993). Synthesis of staphylococcal virulence factors is controlled by a regulatory RNA molecule. EMBO J. 12, 3967-3975. doi: 10.1002/j.1460-2075.1993.tb06074.x

Nudler, E. (2006). Flipping riboswitches. Cell 126, 19-22. doi: 10.1016/j. cell.2006.06.024

Obana, N., Shirahama, Y., Abe, K., and Nakamura, K. (2010). Stabilization of Clostridium perfringens collagenase mRNA by VR-RNA-dependent cleavage in 5' leader sequence. Mol. Microbiol. 77, 1416-1428. doi: 10.1111/j.1365-2958.2010.07258.x

O’Neil, H. S., and Marquis, H. (2006). Listeria monocytogenes flagella are used for motility, not as adhesins, to increase host cell invasion. Infect. Immun. 74, 6675-6681. doi: 10.1128/IAI.00886-06

Oscarsson, J., Tegmark-Wisell, K., and Arvidson, S. (2006). Coordinated and differential control of aureolysin (aur) and serine protease (sspA) transcription in Staphylococcus aureus by sarA, rot and agr (RNAIII). Int. J. Med. Microbiol. 296, 365-380. doi: 10.1016/j.ijmm.2006.02.019

Padalon-Brauch, G., Hershberg, R., Elgrably-Weiss, M., Baruch, K., Rosenshine, I., Margalit, H., et al. (2008). Small RNAs encoded within genetic islands of Salmonella Typhimurium show host-induced expression and role in virulence. Nucleic Acids Res. 36, 1913-1927. doi: 10.1093/nar/gkn050

Papenfort, K., Bouvier, M., Mika, F., Sharma, C. M., and Vogel, J. (2010). Evidence for an autonomous 5' target recognition domain in an Hfq-associated small RNA. Proc. Natl. Acad. Sci. U. S. A. 107, 20435-20440. doi: 10.1073/ pnas. 1009784107

Papenfort, K., Förstner, K. U., Cong, J.-P., Sharma, C. M., and Bassler, B. L. (2015). Differential RNA-seq of Vibrio cholerae identifies the VqmR small RNA as a regulator of biofilm formation. Proc. Natl. Acad. Sci. U. S. A 112, E766-E775. doi: 10.1073/pnas.1500203112

Papenfort, K., Pfeiffer, V., Lucchini, S., Sonawane, A., Hinton, J. C. D., and Vogel, J. (2008). Systematic deletion of Salmonella small RNA genes identifies CyaR, a conserved CRP-dependent riboregulator of OmpX synthesis. Mol. Microbiol. 68, 890-906. doi: 10.1111/j.1365-2958.2008.06189.x 
Papenfort, K., Pfeiffer, V., Mika, F., Lucchini, S., Hinton, J. C., and Vogel, J. (2006). SigmaE-dependent small RNAs of Salmonella respond to membrane stress by accelerating global omp mRNA decay. Mol. Microbiol. 62, 1674-1688. doi: 10.1111/j.1365-2958.2006.05524.x

Papenfort, K., Sun, Y., Miyakoshi, M., Vanderpool, C. K., and Vogel, J. (2013). Small RNA-mediated activation of sugar phosphatase mRNA regulates glucose homeostasis. Cell 153, 426-437. doi: 10.1016/j.cell.2013.03.003

Papenfort, K., and Vanderpool, C. K. (2015). Target activation by regulatory RNAs in bacteria. FEMS Microbiol. Rev. 39, 362-378. doi: 10.1093/femsre/ fuv016

Peñaloza, D., Acuña, L. G., Barros, M. J., Núñez, P., Montt, F., Gil, F., et al. (2021). The small RNA RyhB homologs from Salmonella Typhimurium restrain the intracellular growth and modulate the SPI-1 gene expression within RAW264.7 macrophages. Microorganisms 9:635. doi: 10.3390/ microorganisms 9030635

Pennisi, E. (2010). Shining a light on the genome's "dark matter." Science 330:1614. doi: 10.1126/science.330.6011.1614

Pernitzsch, S. R., Tirier, S. M., Beier, D., and Sharma, C. M. (2014). A variable homopolymeric G-repeat defines small RNA-mediated posttranscriptional regulation of a chemotaxis receptor in Helicobacter pylori. Proc. Natl. Acad. Sci. U. S. A. 111, E501-E510. doi: 10.1073/pnas.1315152111

Pfeiffer, V., Papenfort, K., Lucchini, S., Hinton, J. C. D., and Vogel, J. (2009). Coding sequence targeting by MicC RNA reveals bacterial mRNA silencing downstream of translational initiation. Nat. Struct. Mol. Biol. 16, 840-846. doi: $10.1038 / \mathrm{nsmb} .1631$

Pichon, C., and Felden, B. (2005). Small RNA genes expressed from Staphylococcus aureus genomic and pathogenicity islands with specific expression among pathogenic strains. Proc. Natl. Acad. Sci. U. S. A. 102, 14249-14254. doi: 10.1073/pnas.0503838102

Pichon, C., and Felden, B. (2007). Proteins that interact with bacterial small RNA regulators. FEMS Microbiol. Rev. 31, 614-625. doi: 10.1111/j.1574-6976.2007.00079.x

Pinel-Marie, M. L., Brielle, R., and Felden, B. (2014). Dual toxic-peptide-coding Staphylococcus aureus RNA under antisense regulation targets host cells and bacterial rivals unequally. Cell Rep. 7, 424-435. doi: 10.1016/j.celrep.2014. 03.012

Pinel-Marie, M.-L., Brielle, R., Riffaud, C., Germain-Amiot, N., Polacek, N., and Felden, B. (2021). RNA antitoxin SprF1 binds ribosomes to attenuate translation and promote persister cell formation in Staphylococcus aureus. Nat. Microbiol. 6, 209-220. doi: 10.1038/s41564-020-00819-2

Pitman, S., and Cho, K. H. (2015). The mechanisms of virulence regulation by small noncoding RNAs in low GC gram-positive pathogens. Int. J. Mol. Sci. 16, 29797-29814. doi: 10.3390/ijms161226194

Pourciau, C., Lai, Y.-J., Gorelik, M., Babitzke, P., and Romeo, T. (2020). Diverse mechanisms and circuitry for global regulation by the RNA-binding protein CsrA. Front. Microbiol. 11:601352. doi: 10.3389/fmicb.2020.601352

Quereda, J. J., and Cossart, P. (2017). Regulating bacterial virulence with RNA. Annu. Rev. Microbiol. 71, 263-280. doi: 10.1146/annurev-micro-030117020335

Quereda, J. J., García-Del Portillo, F., and Pucciarelli, M. G. (2016). Listeria monocytogenes remodels the cell surface in the blood-stage. Environ. Microbiol. Rep. 8, 641-648. doi: 10.1111/1758-2229.12416

Quereda, J. J., Ortega, A. D., Pucciarelli, M. G., and García-Del Portillo, F. (2014). The Listeria small RNA Rli27 regulates a cell wall protein inside eukaryotic cells by targeting a long 5'-UTR variant. PLoS Genet. 10:e1004765. doi: 10.1371/journal.pgen.1004765

Raina, M., King, A., Bianco, C., and Vanderpool, C. K. (2018). Dual-function RNAs. Microbiol. Spectr. 6:10. doi: 10.1128/microbiolspec.RWR-0032-2018

Redder, P. (2018). Molecular and genetic interactions of the RNA degradation machineries in Firmicute bacteria. Wiley Interdiscip. Rev. RNA 9. doi: 10.1002/ wrna. 1460

Rice, K. C., Nelson, J. B., Patton, T. G., Yang, S.-J., and Bayles, K. W. (2005). Acetic acid induces expression of the Staphylococcus aureus cidABC and $\operatorname{lrg} \mathrm{AB}$ murein hydrolase regulator operons. J. Bacteriol. 187, 813-821. doi: 10.1128/JB.187.3.813-821.2005

Rochat, T., Bohn, C., Morvan, C., Le Lam, T. N., Razvi, F., Pain, A., et al. (2018). The conserved regulatory RNA RsaE down-regulates the arginine degradation pathway in Staphylococcus aureus. Nucleic Acids Res. 46, 8803-8816. doi: $10.1093 /$ nar/gky584
Rochat, T., Delumeau, O., Figueroa-Bossi, N., Noirot, P., Bossi, L., Dervyn, E., et al. (2015). Tracking the elusive function of Bacillus subtilis Hfq. PLoS One 10:e0124977. doi: 10.1371/journal.pone.0124977

Romeo, T. (1998). Global regulation by the small RNA-binding protein CsrA and the non-coding RNA molecule CsrB. Mol. Microbiol. 29, 1321-1330. doi: 10.1046/j.1365-2958.1998.01021.x

Romilly, C., Lays, C., Tomasini, A., Caldelari, I., Benito, Y., Hammann, P., et al. (2014). A non-coding RNA promotes bacterial persistence and decreases virulence by regulating a regulator in Staphylococcus aureus. PLoS Pathog. 10:e1003979. doi: 10.1371/journal.ppat.1003979

Sáenz-Lahoya, S., Bitarte, N., García, B., Burgui, S., Vergara-Irigaray, M., Valle, J., et al. (2019). Noncontiguous operon is a genetic organization for coordinating bacterial gene expression. Proc. Natl. Acad. Sci. U. S. A. 116, 1733-1738. doi: $10.1073 /$ pnas.1812746116

Said-Salim, B., Dunman, P. M., McAleese, F. M., Macapagal, D., Murphy, E., McNamara, P. J., et al. (2003). Global regulation of Staphylococcus aureus genes by rot. J. Bacteriol. 185, 610-619. doi: 10.1128/JB.185.2.610-619.2003

Salvail, H., Caron, M.-P., Bélanger, J., and Massé, E. (2013). Antagonistic functions between the RNA chaperone Hfq and an sRNA regulate sensitivity to the antibiotic colicin. EMBO J. 32, 2764-2778. doi: 10.1038/emboj.2013.205

Sauder, A. B., and Kendall, M. M. (2018). After the fact(or): posttranscriptional gene regulation in enterohemorrhagic Escherichia coli O157:H7. J. Bacteriol. 200, e00228-e00318. doi: 10.1128/JB.00228-18

Sayed, N., Jousselin, A., and Felden, B. (2012). A cis-antisense RNA acts in trans in Staphylococcus aureus to control translation of a human cytolytic peptide. Nat. Struct. Mol. Biol. 19, 105-112. doi: 10.1038/nsmb.2193

Schoenfelder, S. M. K., Lange, C., Prakash, S. A., Marincola, G., Lerch, M. F., Wencker, F. D. R., et al. (2019). The small non-coding RNA RsaE influences extracellular matrix composition in Staphylococcus epidermidis biofilm communities. PLoS Pathog. 15:e1007618. doi: 10.1371/journal.ppat.1007618

Sedlyarova, N., Shamovsky, I., Bharati, B. K., Epshtein, V., Chen, J., Gottesman, S., et al. (2016). sRNA-mediated control of transcription termination in E. coli. Cell 167, 111.e13-121.e13. doi: 10.1016/j.cell.2016.09.004

Seidl, K., Müller, S., François, P., Kriebitzsch, C., Schrenzel, J., Engelmann, S., et al. (2009). Effect of a glucose impulse on the CcpA regulon in Staphylococcus aureus. BMC Microbiol. 9:95. doi: 10.1186/1471-2180-9-95

Serganov, A., Yuan, Y.-R., Pikovskaya, O., Polonskaia, A., Malinina, L., Phan, A. T., et al. (2004). Structural basis for discriminative regulation of gene expression by adenine- and guanine-sensing mRNAs. Chem. Biol. 11, 1729-1741. doi: 10.1016/j.chembiol.2004.11.018

Sesto, N., Wurtzel, O., Archambaud, C., Sorek, R., and Cossart, P. (2013). The excludon: a new concept in bacterial antisense RNA-mediated gene regulation. Nat. Rev. Microbiol. 11, 75-82. doi: 10.1038/nrmicro2934

Sharma, C. M., Darfeuille, F., Plantinga, T. H., and Vogel, J. (2007). A small RNA regulates multiple $\mathrm{ABC}$ transporter mRNAs by targeting C/A-rich elements inside and upstream of ribosome-binding sites. Genes Dev. 21, 2804-2817. doi: 10.1101/gad.447207

Sievers, S., Lund, A., Menendez-Gil, P., Nielsen, A., Storm Mollerup, M., Lambert Nielsen, S., et al. (2015). The multicopy sRNA LhrC controls expression of the oligopeptide-binding protein OppA in Listeria monocytogenes. RNA Biol. 12, 985-997. doi: 10.1080/15476286.2015.1071011

Sievers, S., Sternkopf Lillebæk, E. M., Jacobsen, K., Lund, A., Mollerup, M. S., Nielsen, P. K., et al. (2014). A multicopy sRNA of Listeria monocytogenes regulates expression of the virulence adhesin LapB. Nucleic Acids Res. 42, 9383-9398. doi: 10.1093/nar/gku630

Singh, R., and Ray, P. (2014). Quorum sensing-mediated regulation of staphylococcal virulence and antibiotic resistance. Future Microbiol. 9, 669-681. doi: $10.2217 / \mathrm{fmb} .14 .31$

Smirnov, A., Förstner, K. U., Holmqvist, E., Otto, A., Günster, R., Becher, D., et al. (2016). Grad-seq guides the discovery of ProQ as a major small RNA-binding protein. Proc. Natl. Acad. Sci. U. S. A. 113, 11591-11596. doi: 10.1073/pnas.1609981113

Sonnleitner, E., Pusic, P., Wolfinger, M. T., and Bläsi, U. (2020). Distinctive regulation of carbapenem susceptibility in Pseudomonas aeruginosa by Hfq. Front. Microbiol. 11:1001. doi: 10.3389/fmicb.2020.01001

Stork, M., Di Lorenzo, M., Welch, T. J., and Crosa, J. H. (2007). Transcription termination within the iron transport-biosynthesis operon of Vibrio anguillarum requires an antisense RNA. J. Bacteriol. 189, 3479-3488. doi: 10.1128/ JB.00619-06 
Svensson, S. L., and Sharma, C. M. (2016). Small RNAs in bacterial virulence and communication. Microbiol. Spectr. 4. doi: 10.1128/microbiolspec. VMBF-0028-2015

Teixidó, L., Cortés, P., Bigas, A., Alvarez, G., Barbé, J., and Campoy, S. (2010). Control by Fur of the nitrate respiration regulators NarP and NarL in Salmonella enterica. Int. Microbiol. 13, 33-39. doi: 10.2436/20.1501.01.108

Thomason, M. K., and Storz, G. (2010). Bacterial antisense RNAs: how many are there, and what are they doing? Annu. Rev. Genet. 44, 167-188. doi: 10.1146/annurev-genet-102209-163523

Thomason, M. K., Voichek, M., Dar, D., Addis, V., Fitzgerald, D., Gottesman, S., et al. (2019). A rhlI 5' UTR-derived sRNA regulates RhlR-dependent quorum sensing in Pseudomonas aeruginosa. MBio 10, e02253-e02319. doi: 10.1128/ mBio.02253-19

Tobe, T., Yen, H., Takahashi, H., Kagayama, Y., Ogasawara, N., and Oshima, T. (2014). Antisense transcription regulates the expression of the enterohemorrhagic Escherichia coli virulence regulatory gene ler in response to the intracellular iron concentration. PLoS One 9:e101582. doi: 10.1371/ journal.pone.0101582

Toledo-Arana, A., Dussurget, O., Nikitas, G., Sesto, N., Guet-Revillet, H., Balestrino, D., et al. (2009). The Listeria transcriptional landscape from saprophytism to virulence. Nature 459, 950-956. doi: 10.1038/nature08080

Toledo-Arana, A., and Lasa, I. (2020). Advances in bacterial transcriptome understanding: from overlapping transcription to the excludon concept. Mol. Microbiol. 113, 593-602. doi: 10.1111/mmi.14456

Toledo-Arana, A., Repoila, F., and Cossart, P. (2007). Small noncoding RNAs controlling pathogenesis. Curr. Opin. Microbiol. 10, 182-188. doi: 10.1016/j. mib.2007.03.004

Tomizawa, J., Itoh, T., Selzer, G., and Som, T. (1981). Inhibition of ColE1 RNA primer formation by a plasmid-specified small RNA. Proc. Natl. Acad. Sci. U. S. A. 78, 1421-1425. doi: 10.1073/pnas.78.3.1421

Tree, J. J., Granneman, S., McAteer, S. P., Tollervey, D., and Gally, D. L. (2014). Identification of bacteriophage-encoded anti-sRNAs in pathogenic Escherichia coli. Mol. Cell 55, 199-213. doi: 10.1016/j.molcel.2014.05.006

Updegrove, T. B., Zhang, A., and Storz, G. (2016). Hfq: the flexible RNA matchmaker. Curr. Opin. Microbiol. 30, 133-138. doi: 10.1016/j.mib.2016.02.003

Urban, J. H., and Vogel, J. (2008). Two seemingly homologous noncoding RNAs act hierarchically to activate glmS mRNA translation. PLoS Biol. 6:e64. doi: 10.1371/journal.pbio.0060064

Vakulskas, C. A., Potts, A. H., Babitzke, P., Ahmer, B. M. M., and Romeo, T. (2015). Regulation of bacterial virulence by Csr (Rsm) systems. Microbiol. Mol. Biol. Rev. 79, 193-224. doi: 10.1128/MMBR.00052-14

Vanderpool, C. K., and Gottesman, S. (2004). Involvement of a novel transcriptional activator and small RNA in post-transcriptional regulation of the glucose phosphoenolpyruvate phosphotransferase system. Mol. Microbiol. 54, 1076-1089. doi: 10.1111/j.1365-2958.2004.04348.x

Vannini, A., Roncarati, D., and Danielli, A. (2016). The cag-pathogenicity island encoded CncR1 sRNA oppositely modulates Helicobacter pylori motility and adhesion to host cells. Cell. Mol. Life Sci. 73, 3151-3168. doi: 10.1007/ s00018-016-2151-z

Wagner, E. G. H., Altuvia, S., and Romby, P. (2002). Antisense RNAs in bacteria and their genetic elements. Adv. Genet. 46, 361-398. doi: 10.1016/ s0065-2660(02)46013-0

Wagner, E. G., and Romby, P. (2015). Small RNAs in bacteria and archaea: who they are, what they do, and how they do it. Adv. Genet. 90, 133-208. doi: 10.1016/bs.adgen.2015.05.001

Wang, C., Chao, Y., Matera, G., Gao, Q., and Vogel, J. (2020). The conserved 3' UTR-derived small RNA NarS mediates mRNA crossregulation during nitrate respiration. Nucleic Acids Res. 48, 2126-2143. doi: 10.1093/nar/gkz1168
Wassarman, K. M., Zhang, A., and Storz, G. (1999). Small RNAs in Escherichia coli. Trends Microbiol. 7, 37-45. doi: 10.1016/S0966-842X(98)01379-1

Waters, L. S., and Storz, G. (2009). Regulatory RNAs in bacteria. Cell 136, 615-628. doi: 10.1016/j.cell.2009.01.043

Weilbacher, T., Suzuki, K., Dubey, A. K., Wang, X., Gudapaty, S., Morozov, I., et al. (2003). A novel sRNA component of the carbon storage regulatory system of Escherichia coli. Mol. Microbiol. 48, 657-670. doi: 10.1046/j.1365-2958.2003.03459.x

Wen, J., and Fozo, E. M. (2014). sRNA antitoxins: more than one way to repress a toxin. Toxins 6, 2310-2335. doi: 10.3390/toxins6082310

Westermann, A. J., Förstner, K. U., Amman, F., Barquist, L., Chao, Y., Schulte, L. N., et al. (2016). Dual RNA-seq unveils noncoding RNA functions in hostpathogen interactions. Nature 529, 496-501. doi: 10.1038/nature16547

Winkler, W., Nahvi, A., and Breaker, R. R. (2002). Thiamine derivatives bind messenger RNAs directly to regulate bacterial gene expression. Nature 419, 952-956. doi: 10.1038/nature01145

Wurtzel, O., Sesto, N., Mellin, J. R., Karunker, I., Edelheit, S., Bécavin, C., et al. (2012). Comparative transcriptomics of pathogenic and non-pathogenic Listeria species. Mol. Syst. Biol. 8:583. doi: 10.1038/msb.2012.11

Yang, B., Feng, L., Wang, F., and Wang, L. (2015). Enterohemorrhagic Escherichia coli senses low biotin status in the large intestine for colonization and infection. Nat. Commun. 6:6592. doi: 10.1038/ncomms7592

Yu, J., and Schneiders, T. (2012). Tigecycline challenge triggers sRNA production in Salmonella enterica serovar Typhimurium. BMC Microbiol. 12:195. doi: 10.1186/1471-2180-12-195

Zhang, Y. F., Han, K., Chandler, C. E., Tjaden, B., Ernst, R. K., and Lory, S. (2017). Probing the sRNA regulatory landscape of $P$. aeruginosa: posttranscriptional control of determinants of pathogenicity and antibiotic susceptibility. Mol. Microbiol. 106, 919-937. doi: 10.1111/mmi.13857

Zhang, H., Zhang, Y., Song, Z., Li, R., Ruan, H., Liu, Q., et al. (2020). sncRNAs packaged by Helicobacter pylori outer membrane vesicles attenuate IL-8 secretion in human cells. Int. J. Med. Microbiol. 310:151356. doi: 10.1016/j. ijmm.2019.151356

Zhao, X., Zhang, Y., and Huang, X. (2018). Pathogenicity-island-encoded regulatory RNAs regulate bacterial virulence and pathogenesis. Microb. Pathog. 125, 196-204. doi: 10.1016/j.micpath.2018.09.028

Zhukova, A., Fernandes, L. G., Hugon, P., Pappas, C. J., Sismeiro, O., Coppée, J.-Y., et al. (2017). Genome-wide transcriptional start site mapping and sRNA identification in the pathogen Leptospira interrogans. Front. Cell. Infect. Microbiol. 7:10. doi: 10.3389/fcimb.2017.00010

Conflict of Interest: The authors declare that the research was conducted in the absence of any commercial or financial relationships that could be construed as a potential conflict of interest.

Publisher's Note: All claims expressed in this article are solely those of the authors and do not necessarily represent those of their affiliated organizations, or those of the publisher, the editors and the reviewers. Any product that may be evaluated in this article, or claim that may be made by its manufacturer, is not guaranteed or endorsed by the publisher.

Copyright (C) 2021 Felden and Augagneur. This is an open-access article distributed under the terms of the Creative Commons Attribution License (CC BY). The use, distribution or reproduction in other forums is permitted, provided the original author(s) and the copyright owner(s) are credited and that the original publication in this journal is cited, in accordance with accepted academic practice. No use, distribution or reproduction is permitted which does not comply with these terms. 